\title{
V. Die militärpolitische Orientierung der SED an der UdSSR und der VR China
}

\section{Die Verhinderung der militärischen Autonomie in der DDR nach sowjetischem Vorbild 1956-1958}

Der Aufbau der NVA erfolgte von Beginn an unter der Anleitung und Aufsicht der sowjetischen Militärberater ${ }^{1}$, die auch schon in den Jahren vorher in den KVP-Einheiten präsent gewesen waren. Auf Vorschlag Ulbrichts wurde ihre Zahl in Übereinstimmung mit dem ZK der KPdSU Anfang 1956 im „Einklang mit der Neuorganisierung der Streitkräfte der DDR" auf 261 militärische Berater und 31 Übersetzer reduziert ${ }^{2}$, Ende des Jahres äußerte nunmehr die sowjetische Seite den Wunsch, ihre Anzahl weiter zu verringern ${ }^{3}, 1958$ gab es dann insgesamt noch 142 sowjetische Militärberater, Instrukteure und Militärdolmetscher in der NVA ${ }^{4}$.

Eine Hauptaufgabe der Militärberater war es, im Interesse der KPdSU sicherzustellen, daß das DDR-Militär grundsätzlich nach dem Muster der sowjetischen Streitkräfte organisiert wurde - etwa im Hinblick auf Strukturen, Dienstvorschriften, Bewaffnung oder Ausbildungsinhalte. Vorgaben und Empfehlungen erhielten die SED- und die NVA-Führung zudem auch vom Kommando der Vereinten Streitkräfte ${ }^{5}$ sowie von Seiten der GSSD. So berichtete beispielsweise offenbar direkt im Anschluß an den Ungarn-Aufstand „eine Gruppe sowjetischer Offiziere, die an den bewaffneten Kämpfen in Budapest teilgenommen" hatten, über ihre Erfahrungen und mögliche Schlußfolgerungen, die sich für die NVA ergaben ${ }^{6}$. Stoph hatte andererseits schon bei der ersten Sitzung des Kollegiums des Ministeriums für Nationale Verteidigung im Februar 1956 dargelegt, man könne zweifellos „nicht alles schematisch übernehmen“. Demzufolge konstatierte er: „Die Dokumente, die Anleitung, Hilfe und Unterstützung[,] die wir von den sowjetischen Beratern bekommen, müssen wir entsprechend den Eigenarten unserer Republik angleichen." 7

1 Vgl. Wenzke, Die Nationale Volksarmee, S. 482.

2 Chruschtschow an Ulbricht, 2. März 1956, SAPMO-BArch, DY 30/J IV 2/202/244, o. Pag.

3 Protokoll der 12. Sitzung der Sicherheitskommission des ZK der SED, 30. November 1956, BA-MA, DVW 1/39554, Bl. 4.

4 Verzeichnis der Dienststellungen für Militärberater, Instrukteure und Militärdolmetscher in der NVA der DDR für 1958, SAPMO-BArch, DY 30/J IV 2/202/66, Bl. 50.

5 Empfehlungen des Vereinten Kommandos der Vereinten Streitkräfte im Warschauer Vertrag, 4. November 1959, BA-MA, VA-01/5059, Bl. $274 \mathrm{ff}$.

6 Protokoll der 12. Sitzung der Sicherheitskommission des ZK der SED, 30. November 1956, BA-MA, DVW 1/39554, Bl. $4 \mathrm{f}$.

7 Protokoll Nr. 1/56 über die Sitzung des Kollegiums des Ministeriums für Nationale Verteidigung, 10. Februar 1956, BA-MA, VA-01/2027, Bl. 26. 
Das Verhältnis zwischen der SED und der NVA wurde jedoch nicht nur direkt durch die Übernahme der praktischen und organisatorischen Vorgaben der Hegemonialmacht beeinflußt, sondern darüber hinaus auch indirekt durch die sich wandelnden zivil-militärischen Beziehungen in der UdSSR selbst. Hier bewirkten nach 1956 vor allem der Einsatz der sowjetischen Streitkräfte beim Volksaufstand in Ungarn und das Wirken des Verteidigungsministers Marschall Gregori K. Schukow nachhaltige Veränderungen, die auch die zivil-militärischen Beziehungen in der DDR beeinflußten und ihren Niederschlag in organisatorischen Reformen in der NVA fanden.

Nachdem Schukow 1955 Verteidigungsminister der UdSSR geworden war, setzte eine verstärkte Autonomisierung der sowjetischen Streitkräfte ein, die mit der Zurückdrängung der Kompetenzen des Parteiapparates innerhalb der militärischen Diskussions- und Entscheidungsprozesse verbunden war: So wurde unter anderem der Einfluß der Politischen Hauptverwaltung im Verteidigungsministerium sowie der Militärräte der Militärbezirke im Hinblick auf die Kontrolle der militärischen Truppenführung eingeschränkt. Das Militär konnte etwa das Mitspracherecht der Politorgane in Kaderentscheidungen nachhaltig zurückdrängen. Zudem wurden die Dienststellungen der Politstellvertreter der Kompanien und der hauptamtlichen Parteisekretäre der Regimenter abgeschafft. Schukows Absicht war es, die uneingeschränkte Befehlsgewalt der Kommandeure durchzusetzen ${ }^{8}$. Im Januar 1956 sagte er: "Certain efforts have been made ... to bring official acts of the commanders under criticism in Party meetings. Such efforts have to be condemned. In supporting strict officers and generals, the mission we are undertaking is to strengthen the commanders' entire authority. "9

Chruschtschow seinerseits zielte nach dem XX. Parteitag der KPdSU im Februar 1956 darauf ab, die „Leninschen Normen des Parteilebens“ auch in den Streitkräften wiederherzustellen. Dies bedeutete, daß das Militär im Rahmen kollektiver Entscheidungsprozesse wieder stärker der Parteikontrolle unterworfen und somit gleichzeitig mit Stalins zentralistischer Militärkonzeption gebrochen werden sollte ${ }^{10}$. In diesem Zusammenhang forderte das ZK der KPdSU im selben Monat, die Angehörigen des Parteiapparates in den Streitkräften sollten sich stärker in der militärischen Ausbildung engagieren und zudem auch deren Durchführung kritisieren ${ }^{11}$.

Die Führung der KPdSU wurde durch den Einsatz der sowjetischen Streitkräfte während des Ungarn-Aufstandes im Oktober und November 1956 in ihrer Grundhaltung weiter bestärkt. Eine niedrige Kampfmoral, Desertionen und auch Fraternisierungen der Soldaten mit den Aufständischen ließen die Parteispitze zur Überzeugung gelangen, die von Schukow beförderte einseitige Professionalisierung der Streitkräfte wirke sich zuungunsten der politischen Zuverlässigkeit aus ${ }^{12}$.

Die SED griff im Anschluß an den XX. Parteitag ihrerseits die Argumentation der KPdSU auf und bezog sie direkt auf die NVA, denn auch sie hielt es in der ge-

8 Avidar, The Party and the Army in the Soviet Union, S. $94 \mathrm{ff}$.

9 Krasnaya Zvezda, 25 January 1956, zit. nach: Avidar, The Party and the Army in the Soviet Union, S. 104.

10 Kolkowicz, The Soviet Military and the Communist Party, S. $137 \mathrm{f}$.

$11 \mathrm{Scott} / \mathrm{Scott}$, The Armed Forces of the USSR, S. $264 \mathrm{f}$.

12 Gosztony, Die Rote Armee, S. $338 \mathrm{ff}$. 
genwärtigen Situation für unabdingbar, den Einfluß der Partei in der Armee zu verstärken. Stoph äußerte im März 1956, es sei notwendig, die Leninschen „Normen des Parteilebens hinsichtlich der kollektiven Führung streng einzuhalten" 13 . Er folgerte daraus: „Es kommt jetzt darauf an, aus diesen großen Erfahrungen, die uns die Kommunistische Partei der Sowjetunion durch den XX. Parteitag übermittelt hat, zu lernen[,] die Eigeninitiative zu entfalten und zu erkennen, dass die größte Kraft, die wir in der Nationalen Volksarmee haben, unsere Sozialistische Einheitspartei ist, unsere Parteiorganisationen und jedes Mitglied."14

Aufgrund der Tatsache, daß sowohl die KPdSU als auch die SED zu diesem Zeitpunkt ähnliche militärpolitische Zielsetzungen verfolgten, bestand offenbar auf beiden Seiten das Bedürfnis, eine Harmonisierung der zukünftig gegenüber dem Militär zu verfolgenden Politik zu erzielen. Bei der Reise einer Regierungsdelegation der DDR in die UdSSR vom 3. bis 8. Januar 1957 dürfte es unter anderem auch in dieser Hinsicht eine Absprache über die zukünftigen Leitlinien gegeben haben ${ }^{15}$.

Im April 1957 bestätigte das ZK der KPdSU dann eine neue „Instruktion für die Parteiorganisationen der KPdSU in der sowjetischen Armee und Flotte". Deren Überarbeitung war bereits auf dem XX. Parteitag beschlossen worden ${ }^{16}$. Die neue Instruktion stärkte zum einen die Stellung der Politischen Hauptverwaltung innerhalb des Verteidigungsministeriums. Als Abteilung des ZK mußte sie jetzt nur noch diesem, nicht aber dem Verteidigungsminister Bericht erstatten ${ }^{17}$. Zum anderen sollte die Instruktion einen "further growth in the activity and militancy of Party organizations, [and] the strengthening of their influence over all aspects of the life and activity of the troops" erzielen ${ }^{18}$. Die Parteiorganisationen waren jetzt dazu berechtigt, „inadequacies in the training and education and in Party-political work on the basis of criticism and self-criticism" aufzudecken ${ }^{19}$. Dies bedeutete zugleich, daß leitende Offiziere ihre Sonderstellung in den Parteiorganisationen verloren und sich auf Mitgliederversammlungen für ihre Arbeit verantworten mußten.

Diese Instruktion diente offensichtlich als Vorlage für die „Instruktion für die Arbeit der Parteiorganisationen der SED in der NVA“, die vom ZK der SED am 21. Mai 1957 zusammen mit den „Bestimmungen für die Arbeit der Politorgane der NVA“ bestätigt wurde ${ }^{20}$. Dafür spricht die zeitliche Nähe der Veröffentlichung sowie die inhaltliche Übereinstimmung 21 .

In den sowjetischen Streitkräften konnte die neue Instruktion in der Praxis jedoch nur eine begrenzte Wirkung entfalten. Das lag unter anderem daran, daß die explizite Kritik an einzelnen Befehlen der Kommandeure auf Parteiversammlungen ausdrücklich verboten blieb, obwohl eine allgemeine Beurteilung der Tätigkeit der

13 Protokoll der Delegiertenkonferenz der Parteiorganisationen der SED im Dienstbereich des Ministeriums für Nationale Verteidigung, 5.-11. März 1956, BA-MA, VA-P-01/036, Bl. 230.

14 Ebenda, Bl. 236.

15 Zeittafel zur Militärgeschichte, S. $74 \mathrm{f}$.

16 Zumal die bis dahin geltende Fassung der Instruktion seit 1934 unverändert in Kraft war.

17 Avidar, The Party and the Army in the Soviet Union, S. 96, $107 \mathrm{f}$.

18 Voennyi vestnik, No. 6, 1957, p. 2, zit. nach: Kolkowicz, The Soviet Military and the Communist Party, S. 131.

19 Petrov, Iu. P.: Partiinoe stroitel'stvo v Sovetskoi Armii I Flote, 1918-1961, Moscow 1964, p. 458, zit. nach: Kolkowicz, The Soviet Military and the Communist Party, S. 132.

20 Vgl. Hübner, Zur Rolle der Partei in der Nationalen Volksarmee, S. 425.

21 Vgl. S. $99 \mathrm{ff}$. 
militärischen Truppenführung gefordert wurde. Zudem wurden die Intentionen der Parteiführung auch durch die Geheimrede Chruschtschows auf dem XX. Parteitag, in der er den Stalinismus verurteilt hatte, konterkariert. Ihr Bekanntwerden erschütterte anscheinend nachhaltig die Autorität der Partei in den Streitkräften ${ }^{22}$.

Der entscheidende Grund jedoch, warum die Reformbestrebungen der KPdSU im Ansatz stecken blieben, war die innenpolitische Krise in der UdSSR im Juni 1957. Die Mehrheit des ZK-Präsidiums, darunter auch Georgi M. Malenkow und Wjatscheslaw M. Molotow, wandte sich offen gegen die Politik Chruschtschows. Dieser konnte sich im Machtkampf um die Führung der KPdSU dank der Unterstützung Schukows jedoch behaupten. Der Verteidigungsminister erlangte daraufhin im Anschluß als erster Militär die Vollmitgliedschaft im ZK-Präsidium ${ }^{23}$. Im Zuge dieser Entwicklung wurden Schukows Stellung und seine militärpolitischen Ziele weiter gestärkt, während den angestrebten Reformen der Parteiführung in den Streitkräften trotz einer breitangelegten Kampagne der Politischen Hauptverwaltung offenbar nur wenig Erfolg beschieden war. Darauf deutet unter anderem auch der Umstand hin, daß die Instruktion in ihrem vollen Wortlaut unveröffentlicht blieb und nur auszugsweise zitiert wurde 24 .

Dieser Zustand der zivil-militärischen Beziehungen in der UdSSR hatte offenbar direkten Einfluß auch auf die Situation in der DDR. Nach der Bestätigung der neuen Vorschriften für die Arbeit der Parteiorganisationen und der Politorgane in der NVA galt es, diese auch zu implementieren. Das Politbüro hatte auf seiner Sitzung am 16. Mai 1957 beschlossen, daß die Erläuterung der „Instruktion für die Arbeit der Parteiorganisationen der SED in der NVA“ und der „Bestimmungen für die Arbeit der Politorgane der NVA“ im Rahmen einer Beratung von Mitgliedern der Parteiführung mit leitenden Parteifunktionären in der NVA erfolgen sollte ${ }^{25}$. Wegen der Auseinandersetzungen im ZK der KPdSU war die SED-Führung auf der „Eggersdorfer Tagung“ am 12./13. Juni 1957 dabei offenbar weitgehend auf sich selbst gestellt. Als Konsequenz scheint es vor allem massive Unklarheiten über Art und Umfang der Verwirklichung der kollektiven Führungsmechanismen gegeben zu haben ${ }^{26}$. Da diese Zielsetzung der SED den Intentionen der sowjetischen Militärführung unter Schukow zu dieser Zeit grundlegend zuwiderlief, dürfte die Unterstützung der sowjetischen Militärberater im Hinblick auf die Umsetzung der neuen Regelungen nur bedingt erfolgt sein. Die SED war somit gezwungen, die Implementierung der Instruktion und der Bestimmungen eigenständig zu leisten. Dies dürfte die bereits vorhandene Neigung, sich auch an der Militärpolitik Chinas zu orientieren, zusätzlich befördert haben ${ }^{27}$.

22 Avidar, The Party and the Army in the Soviet Union, S. $107 \mathrm{f}$.

23 Heller/Nekrich, Geschichte der Sowjetunion, S. 242. Schukow hatte zur entscheidenden ZK-Sitzung Ende Juni ZK-Mitglieder aus der gesamten UdSSR mit Militärflugzeugen einfliegen lassen, wodurch sich die Mehrheitsverhältnisse wieder zugunsten von Chruschtschow veränderten.

24 Kolkowicz, The Soviet Military and the Communist Party, S. $131 \mathrm{ff}$.

25 Protokoll Nr. 21/57 der Sitzung des Politbüros des ZK der SED, 16. Mai 1957, SAPMOBArch, DY 30/J IV 2/2/541, Bl. 6.

$26 \mathrm{Vgl}$. Protokoll der Eggersdorfer Tagung, 12./13. Juni 1957, BA-MA, VA-P-01/037, Bl. $43 \mathrm{ff}$.

27 Schon auf der Eggersdorfer Tagung wurde eine „Schrift über den Arbeitsstil der Parteileitungen" erwähnt, die chinesischen Ursprungs war und bei den Parteifunktionären in der 
Bis zum November 1957 sah sich die SED in ihrer Militärpolitik wegen der fehlenden Rückendeckung durch die UdSSR offensichtlich mit ernstzunehmenden Orientierungsproblemen konfrontiert, die sich äußerst negativ auf die Verwirklichung der neuen Konzeption auswirkten. Rückblickend gab die ZK-Abteilung für Sicherheitsfragen zu, im Hinblick auf die in dieser Zeit „noch vorhandenen Mängel in der Arbeit der Parteiorganisationen in der Nationalen Volksarmee" sei im „Ergebnis der Beratung " in Eggersdorf die „erforderliche Wendung ... nur ungenügend erreicht" worden 28 .

Die Situation änderte sich für die SED jedoch im Anschluß an das sogenannte Oktoberplenum des ZK der KPdSU 1957. Die sowjetische Führung nahm hier den im Frühjahr eingeleiteten militärpolitischen Kurs mit Nachdruck wieder auf und attackierte die ihrer Ansicht nach vorhandenen Autonomisierungsbestrebungen eines Teils der Militärführung. Als deren Urheber identifizierte man Schukow, der daher aus dem ZK ausgeschlossen und als Verteidigungsminister durch Marschall Rodion J. Malinowski ersetzt wurde ${ }^{29}$. Das ZK der KPdSU begründete seinen Entschluß in dem ebenfalls auf dem Oktoberplenum verabschiedeten Beschluß „Über die Verbesserung der parteipolitischen Arbeit in der Sowjetarmee und der Flotte". Schukow wurde vorgeworfen, „gröblich die Leninschen Grundsätze für die Führung der Streitkräfte" verletzt und eine "Linie des Abbaus der Arbeit der Parteiorganisationen, der politischen Organe und der Kriegsräte, der Beseitigung der Führung und Kontrolle der Armee und der Kriegsflotte durch die Partei, ihr Zentralkomitee und die Regierung" verfolgt zu haben 30 .

Das Oktoberplenum entschärfte zugleich auch die militärpolitischen Verunsicherungen innerhalb der SED-Führung. Das Politbüro bekundete umgehend seine „volle Zustimmung“ zu den Beschlüssen des ZK der KPdSU. Sie wurden als „eine große Hilfe für die weitere Durchführung“ der eigenen Beschlüsse „vom Mai dieses Jahres über die Organisierung der politischen Arbeit durch die Parteiorganisationen und Politorgane" in der NVA bezeichnet ${ }^{31}$. Diese Wendung in den Beziehungen zwischen Partei und Armee in der UdSSR motivierte die SED offensichtlich dazu, selbst „die noch vorhandenen Unklarheiten über die Verwirklichung der führenden Rolle der Partei in der Nationalen Volksarmee" auszuräumen und "Maßnahmen zur Erhöhung der Autorität und zur Stärkung der Kampfkraft der Parteiorganisationen zu beschließen“"32. Die SED-Führung ging dabei zunächst davon aus, daß „an den vom Politbüro beschlossenen Bestimmungen und Instruktionen nichts verändert" werden mußte ${ }^{33}$.

Im Dezember 1957 gelangte man dann aber anscheinend zu der Überzeugung, daß es nötig war, „auf Grund der vorhandenen Unzulänglichkeiten in der politi-

NVA allgemein bekannt gewesen zu sein scheint. Protokoll der Eggersdorfer Tagung, 12./13. Juni 1957, BA-MA, VA-P-01/037, Bl. 89.

28 Beitrag zum Bericht des ZK der SED an den Parteitag, 19. Mai 1958, SAPMO-BArch, DY 30/IV 2/12/9, Bl. $58 \mathrm{f}$.

29 Kolkowicz, The Soviet Military and the Communist Party, S. $134 \mathrm{ff}$.

30 Die Stärke der Sowjetarmee liegt in der Führung durch die Partei, S. 3.

31 Stellungnahme des Politbüros des ZK der SED zum Beschluß des ZK der KPdSU, S. 3.

32 Beitrag zum Bericht des ZK der SED an den Parteitag, 19. Mai 1958, SAPMO-BArch, DY 30/IV 2/12/9, Bl. 59.

33 Über die Verbesserung der Arbeit der Politorgane und Parteiorganisationen zur Durchsetzung der führenden Rolle der Partei, 1957, SAPMO-BArch, DY 30/IV 2/12/9, Bl. 4. 
schen Arbeit und der Tätigkeit der Parteiorganisationen einige tiefgreifende Veränderungen vorzunehmen". Auf Initiative der Sicherheitskommission hin wurde beschlossen, „den Parteiorganisationen und den Parteisekretären in ... der Nationalen Volksarmee größere Verantwortung und mehr Rechte" einzuräumen ${ }^{34}$. Der Politbürobeschluß „Über die Rolle der Partei in der NVA“ vom 14. Januar 1958 leitete dementsprechend einige entscheidende organisatorische Veränderungen ein. Hierzu bemerkte die ZK-Abteilung für Sicherheitsfragen: „Eine wesentliche Hilfe bei der Vorbereitung dieses Dokumentes war der Beschluss des Zentralkomitees der KPdSU ,Über die Verbesserung der Parteiarbeit in der Sowjetarmee und Flotte'."35 Diese Aussage ignorierte jedoch bewußt oder unbewußt die Tatsache, daß der Politbürobeschluß vor allem Neuerungen hinsichtlich der Befugnisse der Parteisekretäre enthielt ${ }^{36}$. Diese ließen erkennen, daß die SED wegen der fehlenden Vorgaben von sowjetischer Seite in der Zeit vor dem Oktoberplenum offenbar bereits eine teilweise Umorientierung vollzogen und Elemente der chinesischen Militärkonzeption rezipiert hatte ${ }^{37}$.

Die KPdSU leitete ihrerseits im Anschluß an das Oktoberplenum des ZK weitere Reformschritte ein. Entsprechend der erweiterten Fassung der „Instruktion für die Parteiorganisationen in der sowjetischen Armee und Flotte" vom April 1958 war die Anwendung des Prinzips der Kritik und Selbstkritik „no longer limited to the sphere of Party work but was applied also to the military sphere" 38 . Die uneingeschränkte Befehlsbefugnis der Kommandeure wurde somit spürbar eingeschränkt. Auch parteilose Kommandeure waren jetzt verpflichtet, die kollektiv getroffenen Entscheidungen der Parteiorganisationen anzuerkennen. Anderenfalls drohten sie ihre Dienststellungen zu verlieren ${ }^{39}$. Darüber hinaus beschloß das ZK der KPdSU, die Politische Hauptverwaltung endgültig parallel zum Verteidigungsministerium zu organisieren und ihr die alleinige Verantwortung für die parteipolitische Arbeit in der Armee zu übertragen ${ }^{40}$. Ferner wurden die Militärräte im April 1958 durch ein neues Statut in "true organs of collective leadership“41 mit Entscheidungsbefugnis auch in allen militärischen Fragen umgewandelt: Ihnen gehörten jetzt auch hohe Parteifunktionäre $\mathrm{an}^{42}$.

Diese Neuerungen übernahm die SED zu einem großen Teil im Rahmen der neuen "Instruktion für die Arbeit der Parteiorganisationen der SED in der NVA“ und der „Bestimmungen für die Arbeit der Politorgane der NVA“ vom 17. Juni 1958, deren Überarbeitung das Politbüro bereits im Beschluß „Über die Rolle der

34 Stellungnahme der ZK-Abteilung für Sicherheitsfragen, 30. Dezember 1957, SAPMOBArch, DY 30/IV 2/12/9, Bl. 2.

35 Über die Verbesserung der Arbeit der Politorgane und Parteiorganisationen zur Durchsetzung der führenden Rolle der Partei, 1957, SAPMO-BArch, DY 30/IV 2/12/9, Bl. $4 \mathrm{f}$.

$36 \mathrm{Vgl}$. S. $99 \mathrm{ff}$.

37 Vgl. Kap. V.2. dieser Studie.

38 Petrov, Partiinoe stroitel'stvo v Sovetskoi Armii I Flote, p. 476, zit. nach: Kolkowicz, The Soviet Military and the Communist Party, S. 142.

39 Avidar, The Party and the Army in the Soviet Union, S. $188 \mathrm{ff}$.

40 Ebenda, S. $206 \mathrm{f}$.

41 Petrov, Partiinoe stroitel'stvo v Sovetskoi Armii I Flote, p. 469, zit. nach: Kolkowicz, The Soviet Military and the Communist Party, S. $139 \mathrm{f}$.

42 Avidar, The Party and the Army in the Soviet Union, S. $186 \mathrm{ff}$. 
Partei in der NVA" vom 14. Januar 1958 avisiert hatte ${ }^{43}$. Die Veränderungen gingen zudem auch in das neue „Statut für den Militärrat bei den Kommandos der Militärbezirke, der Seestreitkräfte und der Luftstreitkräfte und Luftverteidigung“ vom 30. Juli 1958 ein $^{44}$.

Im Gegensatz zur SED verabschiedete die KPdSU die überarbeiteten „Bestimmungen für die Politorgane der sowjetischen Armee und Flotte" aber offenbar erst rund vier Monate später: im Oktober 1958. Die Bestimmungen stellten den alten Einfluß der Politorgane in den Einheiten wieder her und erlaubten ihnen, auf alle Tätigkeiten der militärischen Truppenführung Einfluß zu nehmen ${ }^{45}$. Neben der politischen Arbeit nahm der Politstellvertreter einer Einheit auch an der gesamten militärischen Ausbildung teil. Dabei unterstand er allein dem Kommandeur, fungierte jedoch als Vorgesetzter des gesamten übrigen Personalbestandes ${ }^{46}$. Im Unterschied zur NVA behielt der Politstellvertreter seine zentrale Stellung innerhalb des Parteiapparates einer Einheit ${ }^{47}$. Er trug die „unmittelbare Verantwortung für den Zustand der parteipolitischen Arbeit" und war „verpflichtet, ... gemeinsam mit dem Selkretär der Parteiorganisation die Erfüllung der Beschlüsse und der vor der Parteiorganisation stehenden Aufgaben sicherzustellen" 48 . Anders als in der NVA rangierte der Parteisekretär in der Hierarchie weiterhin hinter dem Politstellvertreter. Eine Stärkung der Stellung des Parteisekretärs sowohl innerhalb des Parteiapparates als auch hinsichtlich der Kontrolle der militärischen Truppenführung auf Kosten des Politstellvertreters wurde in den sowjetischen Streitkräften nicht vollzogen.

Allgemein wurde die Etablierung kollektiver Führungsmechanismen in den sowjetischen Streitkräften durch die geänderten Vorschriften von 1958 bestätigt. Auf dieser Basis war es dem Parteiapparat möglich, seinen Einfluß im Verlauf des Jahres sukzessive wieder zu intensivieren. Unter anderem stellte die von den Parteiorganisationen breit geübte Kritik an der Arbeit der Kommandeure deren Autorität massiv in Frage, so wie es in der NVA schon 1957 der Fall gewesen war. Die dadurch verursachten Friktionen zwischen Truppenführung und Parteiapparat wirkten sich nicht zuletzt außerordentlich negativ auf die Moral und die militärische Disziplin in der Truppe aus ${ }^{49}$.

Hierauf reagierte die KPdSU Ende 1958 in gleicher Weise wie die SED. Die Parteiversammlung sollte zukünftig in erster Linie als Sanktionsinstanz dienen, die direkte Einflußnahme auf die militärische Truppenführung im Rahmen kollektiv getroffener Entscheidungen dafür in den Parteileitungen erfolgen ${ }^{50}$. Daher begann man jetzt auch in den sowjetischen Streitkräften Kommandeure in die Parteileitungen zu wählen. So gehörten 1959 vierzehnmal mehr Regimentskommandeure der Parteileitung ihrer Einheit an, als dies 1957 der Fall gewesen war ${ }^{51}$. Anfang 1961

43 Über die Rolle der Partei in der NVA. Protokoll Nr. 4/58 der Sitzung des Politbüros des ZK der SED, 14. Januar 1958, SAPMO-BArch, DY 30/J IV 2/2/576, Bl. 195.

$44 \mathrm{Vgl}$. S. $99 \mathrm{ff}$. und $128 \mathrm{ff}$.

45 Kolkowicz, The Soviet Military and the Communist Party, S. 140 f.

46 Ebenda, S. $377 \mathrm{f}$.

47 Vgl. S. $92 \mathrm{ff}$.

48 Kaljadin, Fragen der parteipolitischen Arbeit in den sowjetischen Streitkräften, S. 30.

49 Kolkowicz, The Soviet Military and the Communist Party, S. $142 \mathrm{ff}$.

50 Avidar, The Party and the Army in the Soviet Union, S. $219 \mathrm{ff}$.

51 Kolkowicz, The Soviet Military and the Communist Party, S. 141. 
war anscheinend die Mehrheit der Kommandeure „elected members of the Party Commitee" 52 .

Diese organisatorische Modifikation - die Verlagerung der kollektiven Führungstätigkeit von den Parteiversammlungen auf die Parteileitungen - war in der NVA schon Anfang 1958 eingeleitet worden. Eine zügige Verwirklichung dieser Maßnahme war hier vermutlich vor allem auch deshalb möglich gewesen, weil der Anteil der Parteimitglieder unter den Offizieren in der NVA von vornherein höher lag als in den sowjetischen Streitkräften. In der NVA gehörten Anfang 1959 bereits knapp 92 Prozent der Offiziere als Mitglieder oder Kandidaten der Partei an ${ }^{53}$, während es in den sowjetischen Streitkräften nur 75,5 Prozent waren ${ }^{54}$. Hier gab es auch jetzt noch Kommandeure und leitende Offiziere, die über keine Parteimitgliedschaft verfügten ${ }^{55}$, was in der NVA zu keiner Zeit möglich gewesen wäre.

Offenbar hatte die SED, die sich formal weitgehend an die Vorgaben der UdSSR hielt, in ihrer Militärpolitik während eines Zeitfensters zwischen 1958 und 1960 genügend Handlungsspielraum, eigene Ansätze zu verwirklichen, die vor allem auf der Rezeption chinesischer Elemente beruhten. Die Tatsache, daß ein Teil dieser Maßnahmen im nachhinein auch von der KPdSU umgesetzt wurden, läßt jedoch nicht die Vermutung zu, der SED sei hier eine Initiativfunktion zugekommen. Zeitlich und inhaltlich nahm die SED jedoch einige strukturelle Modifikationen in den zivil-militärischen Beziehungen in der UdSSR vorweg56. Es läßt sich daher feststellen, daß die NVA Ende der fünfziger Jahre die jeweiligen Veränderungen und Reformen in der Militärpolitik der beiden sozialistischen Großmächte sowohl reflektierte als auch teilweise miteinander verband.

\section{Die „Maoisierung“ der NVA 1957-1960}

Nach dem XX. Parteitag der KPdSU im Februar 1956 kam es zu einer allgemeinen Intensivierung der Beziehungen zwischen der DDR und der VR China. Ulbricht, der im September 1956 am VIII. Parteitag der Kommunistischen Partei Chinas (KPCh) teilnahm, und die chinesische KP-Führung unter Mao Tse-tung einte zu dieser Zeit vor allem die Kritik an der von Chruschtschow betriebenen Entstalinisierung. In den folgenden drei Jahren entwickelte sich dann eine zunehmende Übereinstimmung in ideologischen, politischen und wirtschaftlichen Fragen. ${ }^{57}$ Dabei ergab sich auch eine verstärkte Orientierung der SED an der chinesischen Militärkonzeption ${ }^{58}$.

52 The Party Committee of the Unit, Armed Forces Communist No. 6, 1961, pp. 3-8, zit. nach: Avidar, The Party and the Army in the Soviet Union, S. 222.

53 Vgl. Kap. III.3. dieser Studie.

54 Colton, Commissars, Commanders, and Civilian Authority, S. 18.

55 Kolkowicz, The Soviet Military and the Communist Party, S. 141.

56 Diese These wird durch eine Âßerung Roman von Kolkowicz gestützt, der bemerkt hat: "In timing, substance, and purpose, as well as in the opposition they encountered, the Khrushchevian reforms in the military correspond so closely to military reforms undertaken by the Chinese Communist Party that one is tempted to view the Soviet reforms as modeled on the Chinese." Kolkowicz, The Soviet Military and the Communist Party, S. 138.

57 Die DDR und China 1949 bis 1990, S. 63 ff.

58 Vgl. Froh, Das chinesische Prinzip, S. 8; Hübner, Zur Rolle der Partei in der Nationalen 
Vor diesem Hintergrund war es in gewisser Weise symptomatisch, daß die erste Informationsreise einer Militärdelegation der DDR in das sozialistische Ausland nach China und nicht, wie zu vermuten wäre, in die UdSSR führte. Schon im April 1957 hatte das Politbüro die „Entsendung einer Delegation der Nationalen Volksarmee in die Volksrepublik China“ beschlossen. Diese hatte „die Aufgabe, die Erfahrungen der chinesischen Volksbefreiungsarmee auf den verschiedenen Gebieten in der militärischen Arbeit zu studieren“. Im Anschluß daran sollte im Politbüro eine "gründliche Auswertung" der Ergebnisse dieser Reise erfolgen ${ }^{59}$. Darüber hinaus entsandte die DDR auch ihren ersten Militärattaché am 31. Juli 1957 nach China ${ }^{60}$.

Die Reise der Militärdelegation unter der Leitung von Stoph dauerte vom 3. September bis zum 3. Oktober 1957. Honecker äußerte rückblickend, man habe durch sie Erkenntnisse über „den Aufbau, die politische Arbeit und die militärische Ausbildung " in der VBA gewonnen, was für die eigene Arbeit von „großem Nutzen“ gewesen sei61. Dem umfangreichen Reisebericht ist zu entnehmen, daß die SED bestrebt war, in China Lösungsansätze für eigene militärpolitische Fragen und Probleme zu finden.

Der Bericht enthält unter anderem die Übersetzung einer Rede vom VIII. Parteitag der KPCh, deren Thema „die politische Arbeit in der neuen Etappe des Aufbaus der Armee“ war. Die Hervorhebungen im Text lassen dabei Rückschlüsse zu, in welcher Hinsicht sich die SED Anregungen erhoffte. So interessierten im einzelnen offenbar vor allem die Fragen „Entfremdung “ von Offizieren und Soldaten ${ }^{62}$ sowie von Armee und Bevölkerung ${ }^{63}$, die „Verbindung der Truppen mit den örtlichen Parteikomitees"64, die Anwendung der "Methode der Kritik und Selbstkritik“ in Parteiversammlungen durch die Mannschaften zur Kontrolle der Arbeit von Offizieren $^{65}$, Erziehung statt Strafe als „Hauptmittel zur Erhaltung und Stärkung der Disziplin" 66 und in diesem Zusammenhang die Vorteile eines Einsatzes der Truppen zur „Hilfe des Volkes bei der Produktion"67. In dem Bericht wurde zudem hervorgehoben, die KPCh habe bei der Organisation der Armee die „Erfahrungen der

Volksarmee, S. 423 f.; Lapp, Die Nationale Volksarmee 1956-1990, S. 1952 ff.; Storkmann, Das chinesische Prinzip in der NVA, S. $7 \mathrm{ff}, 24 \mathrm{ff}$.

59 Protokoll Nr. 17/57 der Sitzung des Politbüros des ZK der SED, 16. April 1957, SAPMOBArch, DY 30/J IV 2/2/537, Bl. $205 \mathrm{f}$.

60 Zeittafel zur Militärgeschichte, S. 84. Am 15. Oktober 1957 stimmte das Politbüro Stophs Vorschlag zu, im Gegenzug eine chinesische Militärdelegation in die DDR einzuladen. Protokoll Nr. 44/57 der Sitzung des Politbüros des ZK der SED, 15. Oktober 1957, SAPMOBArch, DY 30/J IV 2/2/564, Bl. 2. Dieser Besuch fand schließlich vom 29. April bis zum 5. Mai 1959 statt. Zeittafel zur Militärgeschichte, S. 110. Zunächst war er für den Herbst 1958 geplant gewesen. Protokoll Nr. 27/58 der Sitzung des Politbüros des ZK der SED, 24. Juni 1958, SAPMO-BArch, DY 30/J IV 2/2/599, Bl. 5 .

61 Aus dem Bericht des Politbüros an das 35. Plenum des ZK der SED, 3.-6. Februar 1958, SAPMO-BArch, DY 30/2059, Bl. 23.

62 Einige Fragen über die politische Arbeit in der neuen Etappe des Aufbaus der Armee - Rede auf dem VIII. Parteitag der KPCh von Tan Dscheng. Bericht der Militärdelegation der NVA in der VR China, 3. September - 3. Oktober 1957, BA-MA, VA-01/2026, Bl. 124.

63 Ebenda, Bl. 125.

64 Ebenda, Bl. 136.

65 Ebenda, Bl. 129.

66 Ebenda, Bl. 133.

67 Ebenda, Bl. 135. 
Kommunistischen und Arbeiterparteien aller Länder, insbesondere der Sowjetunion“ genutzt, „zugleich aber [die] Entwicklung eigener Traditionen und Besonderheiten " berücksichtigt ${ }^{68}$. Resümierend stellte man fest, die Mitglieder der Delegation hätten auf der Reise „wertvolle Anregungen und Hinweise“ erhalten ${ }^{69}$.

Anscheinend reifte im Anschluß an die Reise der Militärdelegation in der SEDFührung verstärkt die Überzeugung, in Anbetracht der spezifischen Bedingungen der zivil-militärischen Beziehungen in der DDR eigene Akzente setzen zu müssen. Entscheidend hierfür dürfte die innenpolitische Krise in der UdSSR gewesen sein sowie die daraus resultierende unzureichende Unterstützung in militärpolitischen Fragen. Wichtiger noch scheint aber die Erkenntnis der SED gewesen zu sein, daß das sowjetische Modell zur Kontrolle und Steuerung des Militärs angesichts der konkreten Bedingungen in der NVA nicht die erwartete Wirkung erzielen konnte. Die chinesische Militärkonzeption dagegen schien in der gegebenen Situation erfolgversprechender zu sein, weshalb sich die SED legitimiert sah, sich an dieser zu orientieren. Wenngleich nicht davon auszugehen ist, daß die SED sich von der Militärkonzeption und der Vorbildrolle der UdSSR grundsätzlich abwenden wollte, so verfügte die KPCh nach Auffassung der SED zu dieser Zeit jedoch über die probateren Lösungsansätze, wenn es darum ging, bestehende Autonomisierungsbestrebungen des Militärs zu unterbinden.

Mit derartigen Tendenzen sah sich auch die KPCh seit Mitte der fünfziger Jahre konfrontiert. Sie waren nicht zuletzt eine Folge der Modernisierung der chinesischen Streitkräfte nach dem Ende des Koreakrieges 1953. Die direkte militärische Konfrontation zwischen der VR China und den USA in diesem Krieg hatte die militärtechnischen und organisatorischen Defizite der VBA deutlich hervortreten lassen. Daher leitete die Parteiführung der KPCh nach Stalins Tod mit Unterstützung der UdSSR umfassende militärische Reformen ein. Treibende Kraft hierbei war der erste Verteidigungsminister Peng Tehuai, der dabei eng mit Schukow kooperierte. Die VR China konnte den Technisierungs- und Organisationsgrad der Armee in der Folgezeit erheblich steigern. Zusätzlich wurden 1955 in der VBA erstmals militärische Dienstgrade eingeführt und auf der Grundlage der „Bestimmungen über den Offiziersdienst" ein eigenständiges Offizierskorps geschaffen. Neben der beabsichtigten Leistungssteigerung der VBA bewirkten diese Veränderungen jedoch auch, daß insbesondere das Offizierskorps ein professionelles und korporatives Selbstverständnis zu entwickeln begann, das die Suprematie der Partei in den Streitkräften in Frage zu stellen schien ${ }^{70}$. Von Seiten der Partei warf man vor allem Peng Tehuai vor, er habe "the Party's absolute leadership over the army" negiert, "to eliminate the system of collective leadership by party committees and to enforce the system of one-man leadership" 71.

68 Materialien für die Auswertung des Freundschaftsbesuches der Militärdelegation der NVA in der VR China. Bericht der Militärdelegation der NVA in der VR China, 3. September 3. Oktober 1957, BA-MA, VA-01/2026, B1. 143.

69 Ebenda, Bl. 146.

70 Jencks, From Muskets to Missiles, S. $48 \mathrm{ff}$.

71 Hold High the Great Red Banner of Mao Tse Tung's Thought. Thoroughly Criticize and Repudiate the Bourgeois Military Line, PR [Peking Review], No. 32 (4. August 1967), p. 44, zit. nach: Jencks, From Muskets to Missiles, S. 51. 
Angesichts der Probleme der SED seit Juni 1957, in der NVA die kollektiven Führungsmechanismen zu implementieren, erwies sich deren Verwirklichung in der VBA als besonders interessant. So wurde bei der Auswertung der Chinareise der NVA-Delegation die Bedeutung der Arbeit der „Parteikomitees“ in der VBA in diesem Zusammenhang hervorgehoben. So hieß es, in der VBA würden im Rahmen der militärischen Truppenführung alle Maßnahmen in den Parteikomitees beraten und im Anschluß durch die Kommandeure Pläne dazu ausgearbeitet ${ }^{72}$. Diese „kollektive Leitung“ werde „zur Stärkung der persönlichen Verantwortung des Einzelleiters für die Kampfführung ununterbrochen aufrecht erhalten" ${ }^{73}$. Insbesondere der Koreakrieg habe bewiesen, daß die kollektive Leitung „in jeder Situation durch die ständige aktive Arbeit der Parteiorganisationen sicherzustellen" sei ${ }^{74}$. Im Gegensatz zum sowjetischen Modell erschien der SED-Führung diese Form der kollektiven Führung offenbar erheblich effizienter zu sein. Denn hier wurde nicht im Rahmen von Parteiversammlungen, sondern in den Leitungen der Parteiorganisationen, den Parteikomitees, Einfluß auf die Entscheidungen der Kommandeure genommen.

Die Parteikomitees waren in der VBA auf allen militärischen Ebenen die zentralen Entscheidungsgremien. Ihre kollektiv beratenen Beschlüsse wurden entsprechend der funktionalen Trennung der Aufgaben in politischen Fragen dem Politkommissar und in militärischen Belangen dem jeweiligen Kommandeur zur Umsetzung übergeben. In die konkrete Ausführung militärischer Befehle und Direktiven durch den Kommandeur sollte das Parteikomitee im Anschluß daher nicht mehr eingreifen. Hierfür war der Kommandeur persönlich verantwortlich. Bei Meinungsverschiedenheiten zwischen Politkommissar und Kommandeur lag die endgültige Entscheidungskompetenz jedoch wiederum beim Parteikomitee ${ }^{75}$. Da der Politkommissar in der VBA zugleich auch das Amt des Parteisekretärs bekleidete, konnte er sich in der Regel gegenüber der militärischen Truppenführung behaup$\operatorname{ten}^{76}$.

Vor allem die Präsenz der Kommandeure in den Parteikomitees dürfte die SED seit Anfang 1958 dazu bewegt haben, die Einheitsführer auch in der NVA in die Parteileitungen $\mathrm{zu}$ wählen. Zudem wurden in Anlehnung an die VBA durch den Politbürobeschluß vom 14. Januar 1958 die Befugnisse der Parteileitungen in bezug auf die Kontrolle der militärischen Führungsprozesse erweitert, ohne daß sich aber in der Person des Parteisekretärs eine vergleichbare Fülle von Kompetenzen konzentriert hätte. Die Dienststellungen des Politstellvertreters und des Parteisekretärs blieben in der NVA sowohl personell als auch organisatorisch weiterhin getrennt. Die Funktion des Parteisekretärs gewann in der NVA jedoch schon allein durch die Verlagerung militärischer Entscheidungen in die Parteileitungen an Gewicht ${ }^{77}$. Die wechselseitige Kontrolle der Politorgane und Parteiorganisationen innerhalb des

72 Materialien für die Auswertung des Freundschaftsbesuches der Militärdelegation der NVA in der VR China. Bericht der Militärdelegation der NVA in der VR China, 3. September -

3. Oktober 1957, BA-MA, VA-01/2026, Bl. 170.

73 Ebenda, Bl. 173.

74 Ebenda.

75 Joffe, Party and Army, S. $59 \mathrm{ff}$.

76 Griffith, The Chinese People's Liberation Army, S. 254.

$77 \mathrm{Vgl}$. S. $99 \mathrm{ff}$. 
Parteiapparates, die in der NVA existierte, wurde in der VBA dagegen vor allem durch die örtlichen Parteileitungen erzielt, deren Führung und Kontrolle sich die Einheiten zusätzlich unterordnen mußten ${ }^{78}$.

Im Gegensatz zu den sowjetischen Streitkräften gab es von Seiten des chinesischen Militärs keine öffentlichen Forderungen nach einer Reduzierung des Parteiapparates in der VBA. Trotzdem zielte Mao im Zuge der „Anti-Rechtsabweichlerkampagne" seit Mitte 1957 darauf ab, mögliche Autonomisierungsbestrebungen durch eine Reihe von Maßnahmen schon im Ansatz zu unterdrücken. Die „AntiRechtsabweichlerkampagne" war eine Reaktion auf die Anfang 1957 initiierte „Hundert-Blumen-Bewegung“. Ihr lag die Intention zugrunde, durch das Zulassen begrenzter Kritik die Effizienz des sozialistischen Systems in China zu steigern. Die Kritik hatte sich jedoch schnell gegen die Partei und ihre Ideologie gerichtet ${ }^{79}$.

Darüber hinaus initiierte Mao die Abkehr vom ökonomischen Modell der UdSSR. Er kritisierte sowohl die einseitige Betonung der Schwerindustrie als auch die übermäßige Zentralisierung der Wirtschaft. Die Anfang 1958 eingeleitete Politik der „Drei Roten Banner“ zielte auf einen eigenständigen Weg zum Aufbau des Sozialismus. Die wirtschaftliche Modernisierung des Landes sollte vor allem dezentral im Rahmen örtlicher Gemeinschaften, der sogenannten Volkskommunen, vorangetrieben werden. Zudem ging es darum, die Agrarproduktion zu erhöhen, um mit den Gewinnen zugleich die Produktivkräfte in der Industrie zu steigern. Mittels der parallel dazu begonnenen Politik des "Großen Sprungs nach vorn" sollten die Volksmassen zudem verstärkt an den gesellschaftlichen Entscheidungsprozessen beteiligt werden. Im Rahmen der neuen „Massenlinie“ beabsichtigte man, unter strikter Kontrolle der Partei den Arbeitsstil der Leitungen durch die Kritik der Bevölkerung zu verbessern, um so Innovationen zu fördern ${ }^{80}$.

Diese neue politische Generallinie der KPCh hatte entscheidenden Einfluß auch auf die chinesische Militärkonzeption. Mao beförderte die grundsätzliche Abkehr von der Militärpolitik der UdSSR. Die VBA sollte zwar modernisiert werden, andererseits aber ihren revolutionären Charakter bewahren ${ }^{81}$. In diesem Zusammenhang hatte Mao deutlich gemacht, "that the party commands the gun und the gun shall never be allowed to command the party" 82 . Diese Politik kulminierte nicht zuletzt in der Entlassung des Verteidigungsministers Peng Tehuai 1959, da dieser weiterhin den Umbau der VBA in eine moderne und professionelle Militärorganisation nach dem Vorbild der sowjetischen Streitkräfte gefordert hatte. Als er in Übereinstimmung mit Chruschtschow zudem die Politik des Großen Sprungs massiv kritisierte, ersetzte Mao ihn im August 1959 durch Lin Biao ${ }^{83}$.

Im Rahmen des "Großen Sprungs nach vorn" war auch in den chinesischen Streitkräften seit Ende 1957 die „Bewegung zur Verbesserung des Arbeitsstils“ proklamiert worden. Auch dort sollte die kollektive Führung eine „Massenbasis“ erhalten. Ziel war es, „durch breite offene Meinungsäußerung, durch breite Diskussion,

78 Tao, Die Geschichte und die besten Traditionen der Volksbefreiungsarmee, S. 729.

79 Jencks, From Muskets to Missiles, S. $51 \mathrm{f}$.

80 Vgl. Gray, Rebellions and Revolutions, S. $306 \mathrm{ff}$.

81 Joffe, Party and Army, S. $47 \mathrm{ff}$.

82 Mao Tse-tung: Selected Military Writings, Peking 1963, p. 272, zit. nach: Joffe, Party and Army, S. 57.

83 Lieberthal, The Great Leap Forward, S. $100 \mathrm{ff}$. 
sozialistische Erziehung, Überprüfung und Verbesserung der Arbeit“ den „Arbeitsstil in der Führung“ und „die Beziehungen zwischen den Unterstellten und den Vorgesetzten" zu verbessern ${ }^{84}$.

Ein fester Bestandteil dieser Politik war der Einsatz der Streitkräfte einschließlich des Offizierskorps in der Produktion. Bereits im Mai 1957 hatte das ZK der KPCh beschlossen, die „leitenden Funktionäre in Schlüsselpositionen aller Parteikomitees" sollten „einen Teil ihrer Zeit in jedem Jahr mit irgendeiner Art von körperlicher Arbeit verbringen" 85 . Die Einheiten der VBA waren dementsprechend jährlich bis zu zwei Monate in zivile Arbeitsprozesse integriert. So leistete das Militär 1958 mehr als 59 Millionen Arbeitstage in der Industrie und Landwirtschaft; das war bereits mehr als doppelt so viel wie im Vorjahr. Als Begründung hieß es, auf diese Weise werde sowohl die Wertschätzung manueller Arbeit durch die Armeeangehörigen als auch ihr kommunistisches Bewußtsein sowie die Einheit der Streitkräfte mit den Volksmassen verbessert. Zudem wirke sich die Maßnahme positiv auf den Führungsstil der militärischen Vorgesetzten aus ${ }^{86}$.

Die SED entwickelte augenscheinlich eine große Affinität zu entscheidenden Elementen der Politik Maos Ende der fünfziger Jahre. Sowohl in der Begrifflichkeit als auch inhaltlich sind bemerkenswerte Übereinstimmungen der politischen Konzepte der SED mit denen der KPCh festzustellen. In der Militärpolitik kam dies auch darin zum Ausdruck, daß die VBA in der zeitgenössischen Fachliteratur der DDR-Streitkräfte behandelt wurde ${ }^{87}$. Zudem fand sich bereits im Politbürobeschluß „Über die Rolle der Partei in der NVA“ vom 14. Januar 1958 die Forderung nach der "Verbesserung ... des Arbeitsstils" und einer "Orientierung auf das Neue" 88 .

Auf dem V. Parteitag der SED vom 10. bis 16. Juli 1958 verkündete die SED-Führung die programmatischen Grundsätze, anhand derer die geplante „Vollendung des Aufbaus des Sozialismus" in der DDR erreicht werden sollte. Ähnlich wie die KPCh formulierte auch die SED die Zielsetzung, die wirtschaftliche Produktivkraft erheblich zu steigern. Bis 1961 sollte so die Bundesrepublik im Pro-Kopf-Verbrauch bei Nahrungsmitteln und Konsumgütern übertroffen werden. Vermutlich zusätzlich animiert durch Maos Volkskommunenbewegung wurde auf dem Parteitag auch beschlossen, die sozialistische Entwicklung der Landwirtschaft und damit deren Kollektivierung zu beschleunigen ${ }^{89}$.

Darüber hinaus regte Ulbricht auf dem V. Parteitag in Anlehnung an die Massenlinie der chinesischen KP die „regelmäßige Teilnahme von Funktionären der Partei, des Staatsapparates und der Massenorganisationen an der Produktionsarbeit oder am nationalen Aufbauwerk“ an ${ }^{90}$. Auf der Grundlage der "praktischen Arbeit an

84 Tao, Die Geschichte und die besten Traditionen der Volksbefreiungsarmee, S. $730 \mathrm{f}$.

85 Teilnahme von leitenden Kadern verschiedener Ebenen an körperlicher Arbeit. Vom ZK der KP Chinas am 10. Mai 1957 herausgegebene Richtlinie, SAPMO-BArch, DY 30/IV 2/20/118, Bl. 10.

86 Joffe, Party and Army, S. 87.

87 Vgl. u.a. Die Entwicklung der chinesischen Kriegskunst, S. $113 \mathrm{ff}$.

88 Über die Rolle der Partei in der NVA. Protokoll Nr. 4/58 der Sitzung des Politbüros des ZK der SED, 14. Januar 1958, SAPMO-BArch, DY 30/J IV 2/2/576, Bl. $193 \mathrm{f}$.

89 Vgl. Weber, DDR: Grundriß der Geschichte 1945-1990, S. 79, 87.

90 Stenografische Niederschrift des V. Parteitages der SED, 10.-16. Juli 1958, SAPMO-BArch, DY $30 / \mathrm{IV} 1 / \mathrm{V} / 1, \mathrm{Bl} .327$. 
der Basis“, so Ulbricht, entwickele die Partei „neue Arbeitsmethoden" 91 und erreiche die „Verbesserung des Arbeitsstils aller Parteimitglieder". Auf diese Weise werde das „formale Administrieren und der seelenlose Bürokratismus überwunden" und sowohl die Parteiarbeit als auch die Arbeit der Mitarbeiter des Staatsapparates "enger mit der Praxis verbunden" $"$.

Vor dem Hintergrund dieser Forderung äußerte Honecker in bezug auf die NVA, die „Beziehungen zwischen den Angehörigen der bewaffneten Kräfte und den Werktätigen, insbesondere der Arbeiterklasse“, seien "noch enger zu gestalten“93. Dabei müsse nicht zuletzt der „sozialistischen Bewusstseinsbildung“ der Offizierskader „eine viel grössere Aufmerksamkeit als bisher" geschenkt werden ${ }^{94}$. Honecker sagte: „Gleichzeitig damit stehen wir vor der Aufgabe, jenen Offizieren[,] die noch nicht über genügende Produktionserfahrungen verfügen, zu helfen, sich solche Erfahrungen durch die zeitweilige Tätigkeit in einem sozialistischen Grossbetrieb, durch ihre unmittelbare Mitarbeit in der Produktion ... anzueignen." Der Produktionseinsatz werde allen Armeeangehörigen helfen, „sich fester mit dem sozialistischen Aufbau zu verbinden und bestehende Mängel in den Einheiten, insbesondere in den Beziehungen zwischen Offizieren und Mannschaften, im Interesse der Erhöhung der Kampf- und Einsatzbereitschaft zu beseitigen" 95 .

Mitte 1958 gab es nach Angaben der ZK-Abteilung für Sicherheitsfragen 5458 NVA-Offiziere, die noch niemals in der Produktion tätig gewesen waren. Zu diesen gehörten auch 558 Politoffiziere; dies waren immerhin 20 Prozent aller Politkader in der NVA ${ }^{96}$. Honecker war schon im Juni 1958 vom Politbüro damit beauftragt worden, zu überprüfen, wie die Offiziere ohne Produktionserfahrung „für einige Zeit zur Teilnahme am sozialistischen Aufbau" delegiert werden konnten"7.

Die Forderungen des V. Parteitages wurden im Rahmen der Direktive des Ministers für Nationale Verteidigung vom 3. Oktober 1958 umgesetzt. Nunmehr konnten NVA-Angehörige zur „Erlangung von Produktionserfahrungen in der sozialistischen Industrie sowie der sozialistischen Land- und Forstwirtschaft" vom Dienst in der NVA freigestellt werden ${ }^{98}$.

Im einzelnen sah die Direktive vor, daß vom 1. November 1958 an alle Offiziersschüler des letzten Lehrjahres, die vor Eintritt in die NVA nicht mindestens ein Jahr in der Produktion tätig gewesen waren, nach ihrer Ernennung zum Offizier hierfür

91 Ebenda, B1. 323-325.

92 Ebenda, Bl. 327.

93 Stenografische Niederschrift des V. Parteitages der SED, 10.-16. Juli 1958, SAPMO-BArch, DY 30/IV 1/V/5, Bl. 1916.

94 Ebenda.

95 Ebenda, Bl. $1916 \mathrm{ff}$.

96 Bericht über den Stand der Durchführung der Beschlüsse des V. Parteitages der SED in der NVA, 20. Oktober 1958, SAPMO-BArch, DY 30/IV 2/12/10, Bl. 248.

97 Protokoll Nr. 26/58 der Sitzung des Politbüros des ZK der SED, 17. Juni 1958, SAPMOBArch, DY 30/J IV 2/2/598, Bl. 5.

98 Freistellung von Angehörigen der NVA zur Erlangung von Produktionserfahrung in der sozialistischen Industrie sowie der sozialistischen Land- und Forstwirtschaft. Direktive Nr. 6/58 des Ministers für Nationale Verteidigung, 3. Oktober 1958, BA-MA, VA-01/4372, Bl. 40. Im Februar 1959 wurde diese Maßnahme explizit auch auf die Politoffiziere und Parteisekretäre ausgedehnt. Freistellung von Politoffizieren und Parteisekretären für die Arbeit in der sozialistischen Produktion. Direktive Nr. 1/59 des Ministers für Nationale Verteidigung, 4. Februar 1959, BA-MA, VA-01/4839, Bl. 260 f. 
für etwa ein Jahr freigestellt werden sollten ${ }^{99}$. Nach Angaben von Ulbricht wurden 1958 bereits 600 Absolventen der Offiziersschulen in die Produktion entsandt ${ }^{100}$. 1959 sollte dies für weitere 638 und 1960 für 595 Absolventen gelten. Ferner hatten die Offiziersschüler des 1. und 2. Lehrjahres ihre Offiziersausbildung zu unterbrechen und die fehlende Produktionserfahrung 1959 für die Dauer eines Jahres nachzuholen ${ }^{101}$.

Die überarbeitete Fassung der Direktive vom 20. November 1958 legte dann im Detail fest, wie die betreffenden Offiziere vom 1. Januar 1959 an zur Aneignung sozialistischer Produktionserfahrungen vom aktiven Dienst freizustellen waren. Für die Geburtsjahrgänge ab 1930 galt dies für die Dauer von bis zu fünf Monaten und für die Geburtsjahrgänge bis 1929 kurzfristig bis zu vier Wochen. Ausgenommen von dieser Regelung blieben Offiziere der Fachrichtungen Flieger und medizinische Dienste ${ }^{102}$. Der Grund hierfür war offenbar die zu der Zeit äußerst angespannte Personallage in diesen hochqualifizierten Verwendungen. Der ohnehin bestehende allgemeine Mangel an Offizieren in der NVA, 1958 gab es einen Fehlbestand von $1035^{103}$, dürfte zudem der Grund dafür gewesen sein, warum sich ständig nicht mehr als etwa fünf Prozent des Gesamtbestandes der Offiziere in der Produktion befinden sollten ${ }^{104} .1959$ wurden auf der Grundlage der Direktive insgesamt 1706 Offiziere für den Produktionseinsatz freigestellt ${ }^{105}$. Ursprünglich hatte man bis 1960 sogar 25 Prozent des gesamten Offiziersbestandes „periodisch in der Produktion arbeiten lassen" wollen ${ }^{106 .}$

So ungewöhnlich diese Erziehungsmaßnahme für sich genommen bereits war, zwei Umstände haben vermutlich zusätzlich für Unmut im Offizierskorps ge-

99 Freistellung von Angehörigen der NVA zur Erlangung von Produktionserfahrung in der sozialistischen Industrie sowie der sozialistischen Land- und Forstwirtschaft. Direktive Nr. 6/58 des Ministers für Nationale Verteidigung, 3. Oktober 1958, BA-MA, VA-01/4372, Bl. 42.

100 Ulbricht an Chruschtschow, 27. Februar 1959, SAPMO-BArch, DY 30/J IV 2/202/66, Bl. 65 .

101 Auskunftsbericht über die Lage im Offiziers-Bestand nach dem Stand vom 1. August 1958 sowie die sich daraus ergebenden Maßnahmen bei der Freistellung von Offizieren für die Produktionstätigkeit, 4. September 1958, BA-MA, VA-01/5495, Bl. 66.

102 Kurzfristige Delegierung von Offizieren zur Aneignung von Produktionserfahrungen in der sozialistischen Industrie sowie der sozialistischen Land- und Forstwirtschaft. Direktive Nr. 11/58 des Ministers für Nationale Verteidigung, 20. November 1958, BA-MA, VA-01/4372, Bl. 186.

103 Auskunftsbericht über die Lage im Offiziers-Bestand nach dem Stand vom 1. August 1958 sowie die sich daraus ergebenden Maßnahmen bei der Freistellung für die Produktionstätigkeit, 4. September 1958, BA-MA, VA-01/5495, Bl. 66.

104 Kurzfristige Delegierung von Offizieren zur Aneignung von Produktionserfahrungen in der sozialistischen Industrie sowie der sozialistischen Land- und Forstwirtschaft. Direktive Nr. 11/58 des Ministers für Nationale Verteidigung, 20. November 1958, BA-MA, VA-01/4372, Bl. 187.

105 Bericht und Vorschläge zur Durchführung des Beschlusses vom 30. Juli 1958 über die Freistellung von Offizieren zur Aneignung von Produktionserfahrungen in der sozialistischen Industrie, Land- und Forstwirtschaft. Protokoll der 2. Sitzung des Nationalen Verteidigungsrates der DDR, 15. Juni 1960, BA-MA, DVW 1/39459, Bl. 61.

106 Stenografische Niederschrift der 4. Tagung des ZK der SED. 15.-17. Januar 1959, SAPMOBArch, DY 30/IV 2/1/214, Bl. 283. 
sorgt ${ }^{107}$. Zum einen unterlagen die Offiziere während ihrer Freistellung weiter „allen Bestimmungen hinsichtlich ihrer Rechte und Pflichten für die Offiziere des aktiven Dienstes"; sie blieben somit auch ihren Kommandeuren disziplinarisch unterstellt. Zum anderen wurden die Offiziere in der Regel nur nach den gültigen Tarifen der jeweiligen Betriebe entlohnt ${ }^{108}$.

Nicht minder folgenreich für das Offizierskorps der NVA war eine weitere Erziehungsmaßnahme, die die SED 1959 direkt von der KPCh übernahm: der Einsatz von Offizieren als Soldaten in der Truppe. Im Zuge der Bewegung gegen Bürokratismus, Dogmatismus, Subjektivismus und Konservatismus ${ }^{109}$ hatte die Politische Hauptverwaltung der chinesischen VBA am 20. September 1958 eine „Verordnung über den jährlichen einmonatigen Dienst der Offiziere in den Kompanien als einfache Soldaten" beschlossen. Junge Offiziere der VBA, die bisher weder in der Produktion tätig gewesen waren noch als Mannschaftsdienstgrad gedient hatten, sollten in ihrem ersten Jahr sogar zwischen sechs und zwölf Monate als einfache Soldaten in den Einheiten eingesetzt werden ${ }^{110}$. Diese Maßnahme, die schon 1957 eingeleitet worden war, zielte vor allem darauf ab, die fortschreitende Professionalisierung des Offizierskorps zu bekämpfen. Sie sollte die Entstehung eines elitären und korporativen Selbstverständnisses unter den Offizieren verhindern und deutlich machen, daß die Existenz der verschiedenen Dienstgradgruppen in der VBA ausschließlich auf der funktionalen Aufgabenteilung beruhte. Während Ende 1958 rund 10000 Offiziere einschließlich 70 Generale als Mannschaftsdienstgrade in der Truppe dienten, waren es im Februar 1959 bereits 150000 Offiziere, darunter 160 Generale 111.

Auf der 4. Tagung des ZK im Januar 1959 wurde nicht nur in dieser Frage deutlich, wie stark die allgemeine Orientierung der Parteiführung an der Politik der KPCh und ihrer revolutionären Programmatik gediehen war. Ulbricht konstatierte, bei der Umgestaltung der Gesellschaft müsse vor allem die „Selbsterziehung und Erziehung der Menschen zu bewußten Sozialisten“ sowie die „Gestaltung richtiger Beziehungen zwischen der Partei, der Staatsmacht und den Volksmassen“ im Mittelpunkt stehen ${ }^{112}$. Das erfordere die „Beseitigung der Methode des formalen Administrierens, die Verbindung kollektiver, auf die Erfahrungen der Massen gestützter Beschlüsse der Führung mit der Hilfe und ständigen Kontrolle bei der Durchführung der Beschlüsse an der Basis". Er forderte, die Partei müsse ständig von den Massen lernen, „das Neue in der Praxis der Massen“, die „neuen Formen und Methoden der gemeinschaftlichen Arbeit und des kollektiven Lebens" erkennen und

107 Vgl. Kap VI. dieser Studie.

108 Bei Freistellungen bis zu vier Wochen erhielten sie 70 Prozent ihrer bisherigen Dienstbezüge. Kurzfristige Delegierung von Offizieren zur Aneignung von Produktionserfahrungen in der sozialistischen Industrie sowie der sozialistischen Land- und Forstwirtschaft. Direktive Nr. 11/58 des Ministers für Nationale Verteidigung, 20. November 1958, BA-MA, VA-01/4372, Bl. $187 \mathrm{f}$.

109 Jencks, From Muskets to Missiles, S. 52.

110 Verordnung über den jährlichen einmonatigen Dienst der Offiziere in den Kompanien als einfache Soldaten. Handakte des Ministers für Nationale Verteidigung über den Einsatz von Offizieren als Soldaten in der Truppe, 1958-1959, BA-MA, VA-01/6312, Bl. $1 \mathrm{f}$.

111 Joffe, Party and Army, S. $133 \mathrm{f}$.

112 Stenografische Niederschrift der 4. Tagung des ZK der SED, 15.-17. Januar 1959, SAPMOBArch, DY 30/IV 2/1/214, Bl. $39 \mathrm{f}$. 
fördern ${ }^{113}$. Für die „Entwicklung des neuen Arbeitsstils“ sei es von herausragender Bedeutung, daß die SED „sorgfältiger die Vorschläge und Kritik der Volksmassen“ auswerte und nicht zuletzt „durch die zeitweise Teilnahme der Funktionäre an der Produktionsarbeit oder im Nationalen Aufbauwerk ein enges Vertrauensverhältnis zu den Werktätigen" schaffe ${ }^{114}$.

In diesem Zusammenhang nannte Ulbricht explizit auch den Produktionseinsatz von NVA-Offizieren. Die ZK-Abteilung für Sicherheitsfragen hatte seinen Angaben zufolge auf Initiative der Sicherheitskommission hin auch die „Zweckmäßigkeit des zeitweiligen Einsatzes von Generalen und Offizieren in den unteren Einheiten als Soldaten, Gefreite und Unteroffiziere geprüft" und vorgeschlagen, diese sollten jährlich „vier bis zu zwölf Wochen als Soldaten Dienst tun“. Er betonte, daß auf diese Weise eine „schnellere und wesentliche Verbesserung der sozialistischen Beziehungen zwischen Offizieren und Soldaten erzielt" werden könne, da die Offiziere sowohl „unmittelbar das Leben in der Truppe, die Sorgen und Nöte der Soldaten" als auch die "Auswirkungen von Befehlen durch ihre eigene Erfahrung" kennenlernten, wodurch sie nicht zuletzt ihren Arbeitsstil verbessern würden ${ }^{115}$.

Die SED-Führung hatte keine Scheu, diese Maßnahme der KPCh ein Vierteljahr nach ihrer umfassenden Verwirklichung in der VBA ebenfalls direkt in der NVA einzuführen. Hoffmann erklärte hierzu: „Die chinesischen Genossen haben in dieser Frage schon wichtige Erfahrungen gesammelt. Wir haben mit ihnen eine längere Aussprache gehabt und bekommen von ihnen Artikel und sonstige Berichte darüber, die wir entsprechend unseren Bedingungen werden anwenden müssen."116

Motiv für die Übernahme auch dieses Erziehungsinstrumentes dürfte zudem der Umstand gewesen sein, daß man bei der Schaffung eines neuen Offizierskorps aus Sorge um die politische Zuverlässigkeit der militärischen Führungskader auch auf zivile Parteifunktionäre zurückgegriffen hatte. Diese waren zumeist ohne umfassende fachliche Ausbildung direkt in einer militärischen Leitungsfunktion oder im Ministerium für Nationale Verteidigung selbst eingesetzt worden. Offenbar erwies es sich aber rasch als Nachteil, daß gerade diese Offiziere nur über wenig Truppenerfahrung verfügten. So besaßen Anfang 1959 insgesamt mehr als 60 Prozent der Offiziere des Ministeriums keinerlei Erfahrungen im einfachen Truppendienst: weder als Soldat noch als Offizier. In der Politischen Verwaltung betraf dies von 88 Offizieren 69 und in der Verwaltung Kader von 58 Offizieren $53^{117}$.

Hoffmann empfand diese Zahlen als „etwas erschreckend“. Ursache für eine solche Zusammensetzung des Offizierspersonals sei jedoch „nicht böser Wille“ der leitenden Genossen gewesen, sondern auf die Notwendigkeit zurückzuführen, „in relativ kurzer Zeit eine Armee aufzubauen“. Man habe „nicht auf alte Offiziers-

113 Ebenda, Bl. 46.

114 Ebenda, Bl. 72. Hieran knüpfte unmittelbar auch eine Anordnung des Ministers für Nationale Verteidigung über die "grundlegende Veränderung des Arbeitsstils" an. Maßnahmen zur grundlegenden Veränderung des Arbeitsstils der Leitung des Ministeriums für Nationale Verteidigung, der Kommandos und der höheren Stäbe. Anordnung Nr. 5/59 des Ministers für Nationale Verteidigung, 3. Februar 1959, BA-MA, VA-01/2898, Bl. $36 \mathrm{ff}$.

115 Stenografische Niederschrift der 4. Tagung des ZK der SED, 15.-17. Januar 1959, SAPMOBArch, DY 30/IV 2/1/214, Bl. $75 \mathrm{f}$.

116 Ebenda, Bl. 284.

117 Ebenda, BI. 286. 
kader der faschistischen [Wehrmacht] in breitem Maße zurückgreifen“ können, „sondern nur in Einzelfällen" 118 .

Sowohl die zunehmende Distanz vieler Stabsoffiziere zu Fragen des Truppendienstes als auch die in den Reihen der NVA-Offiziere vorhandene korporative Attitüde, die die SED im Hinblick auf die Schaffung eines neuen, sozialistischen Offizierskorps zu überwinden gehofft hatte, veranlaßte das Politbüro in Anlehnung an die KPCh am 20. Januar 1959, den „zeitweiligen Einsatz von Generalen, Admiralen und Offizieren in den unteren Einheiten als Soldaten" zu beschließen. Er sollte jährlich vier Wochen dauern ${ }^{119}$. Zur Begründung hieß es, in Durchführung des Politbürobeschlusses vom 14. Januar 1958 sei trotz „unbestreitbarer Fortschritte ... der notwendige Umschwung in der sozialistischen Erziehung, im Arbeitsstil und der Verbesserung des Klassenverhältnisses zwischen Offizier und Soldat jedoch noch nicht erreicht" worden. Daher zielte der Beschluß nicht zuletzt auf die „Überwindung spießbürgerlicher und bürokratischer Gewohnheiten"120.

Die SED plante zunächst, zwischen dem 1. Mai und dem 15. November 1959 „im beschränkten Umfang“ einen Teil der Offiziere des Ministeriums, der Leitungen und Stäbe der Militärbezirke, Seestreitkräfte, Luftstreitkräfte und Luftverteidigung, der Divisionen sowie der Militärakademie und der Offiziersschulen in der Truppe als Soldat dienen zu lassen, um hinsichtlich dieser Maßnahme Erfahrungen zu sammeln $^{121}$. Darüber hinaus waren alle Parteisekretäre und verantwortlichen Politarbeiter „vorrangig“ einzuplanen ${ }^{122} .1959$ leisteten daraufhin jedoch zunächst nur 159 Offiziere Dienst als Soldat in der Truppe ${ }^{123}$.

Ab 1960 sollte der Beschluß dann „für alle Offiziere der Nationalen Volksarmee bis zum 50. Lebensjahr“ gelten, es sei denn, sie waren „körperlich oder gesundheitlich dazu nicht in der Lage". Zusätzlich wollte man Offizieren und Generalen, die über keine Truppenpraxis verfügten oder schon lange Jahre nicht mehr in der Truppe tätig waren, die Möglichkeit geben, etwa als Zugführer oder Kompaniechef eingesetzt zu werden. Das Politbüro beauftragte Stoph, der Sicherheitskommission im November 1959 „über die gesammelten Erfahrungen und die erreichten Ergebnisse zu berichten" und Maßnahmen zur Gewährleistung des Einsatzes aller Offiziere ab 1960 zum Dienst als Soldat in der Truppe vorzuschlagen. Zudem wurde

118 Ebenda, Bl. 285.

119 Beschluß über den zeitweiligen Einsatz von Generalen, Admiralen und Offizieren in den unteren Einheiten als Soldaten. Protokoll Nr. 4/59 der Sitzung des Politbüros des ZK der SED, 20. Januar 1959, SAPMO-BArch, DY 30/J IV 2/2/628, Bl. 10, 152.

120 Arbeitsprotokoll Nr. 4/59 der Sitzung des Politbüros des ZK der SED, 20. Januar 1959, SAPMO-BArch, DY 30/J IV 2/2A/678, o. Pag.

121 Beschluß über den zeitweiligen Einsatz von Generalen, Admiralen und Offizieren in den unteren Einheiten als Soldaten. Protokoll Nr. 4/59 der Sitzung des Politbüros des ZK der SED, 20. Januar 1959, SAPMO-BArch, DY 30/J IV 2/2/628, B1. 152.

122 Grundsätze über den jährlich 4-wöchigen Dienst der Offiziere der NVA als Soldaten in den Kompanien. Protokoll Nr. 4/59 der Sitzung des Politbüros des ZK der SED, 20. Januar 1959, SAPMO-BArch, DY 30/J IV 2/2/628, Bl. 155.

123 Bericht und Vorschläge zur Durchführung des Beschlusses vom 20. Januar 1959 über die zeitweilige Dienstleistung der Offiziere, Generale und Admirale als Soldat bzw. Unteroffizier in der Truppe. Protokoll der 2. Sitzung des Nationalen Verteidigungsrates der DDR, 15. Juni 1960, BA-MA, DVW 1/39459, Bl. 64. 
Dölling angewiesen, bis zum 15. Februar 1959 die „politische Vorbereitung“ der Durchführung des Beschlusses sicherzustellen ${ }^{124}$.

Die Anordnung des Ministers für Nationale Verteidigung, die den Politbürobeschluß implementierte, regelte ferner, daß die jeweiligen Kommandeure gemeinsam mit den Parteileitungen festlegen sollten, „welche Offiziere zu welcher Zeit ihren Dienst als Soldat in einer bestimmten Einheit" zu leisten hatten. Offiziere, die 1960 für die zeitweilige Tätigkeit in der Produktion vorgesehen waren, blieben in diesem Jahr vom Dienst als Soldat freigestellt. Die Offiziere sollten ihren Dienst als Soldat in den eigenen Truppenteilen und Verbänden versehen ${ }^{125}$. Dies dürfte für einige Komplikationen gesorgt haben, da es so einerseits wahrscheinlich war, daß der Personalbestand die Offiziere kannte, diese andererseits aber anscheinend den Auftrag hatten, zunächst „konspirativ“ zu agieren und „unerkannt zu bleiben“ 126 .

Weiterhin sah die Anordnung vor, daß die Generale und Offiziere während der Dauer ihres Einsatzes „ausschließlich die in den Dienstvorschriften, Befehlen und Anordnungen für Soldaten festgelegten Rechte und Pflichten" hatten. In Übereinstimmung mit der Linie der chinesischen VBA mußten die Offiziere die Uniformen der Soldaten tragen und gemeinsam mit diesen „wohnen, schlafen, essen und arbeiten“. Die Kommandeure hatten dabei streng darauf $\mathrm{zu}$ achten, daß den Offizieren weder Privilegien eingeräumt wurden noch daß es zu „Überspitzungen“ bei den an sie gestellten Forderungen kam. Nach Abschluß der Dienstzeit hatten die Kompaniechefs zusammen mit den Parteiorganisationen über jeden Offizier eine Beurteilung für die zuständige Parteileitung und den Vorgesetzten anzufertigen ${ }^{127}$.

Direkt im Anschluß an die 4. ZK-Tagung scheint die Parteiführung im Zusammenhang mit dem Politbürobeschluß vom 20. Januar 1959 mit einigen Problemen konfrontiert gewesen $\mathrm{zu}$ sein, die jedoch nicht durch die militärische Truppenführung, sondern vielmehr durch den Parteiapparat in der NVA verursacht worden waren. Denn die Parteileitung der Politischen Verwaltung hatte auf der Grundlage der ZK-Beschlüsse entschieden, die Mitglieder ihrer Parteiorganisation sollten freiwillig in der Truppe als Soldat dienen. Darüber hinaus aber veröffentlichte die Parteileitung in der Zeitung „Die Volksarmee“ einen Artikel, in dem die Parteiorganisationen der "ganzen Armee“ aufgerufen wurden, „es ebenso zu machen“128.

Hoffmann bemerkte hierzu, „bei allem guten Willen“ der Parteileitung der Politischen Verwaltung sei "dies eine falsche Handlung gewesen“, die politisch "gewisse Schwierigkeiten mit sich bringen“ werde. Man solle die 4.ZK-Tagung nicht auf diese „untergeordneten Maßnahmen“ reduzieren. Hoffmann konstatierte: „Wir

124 Beschluß über den zeitweiligen Einsatz von Generalen, Admiralen und Offizieren in den unteren Einheiten als Soldaten. Protokoll Nr. 4/59 der Sitzung des Politbüros des ZK der SED, 20. Januar 1959, SAPMO-BArch, DY 30/J IV 2/2/628, Bl. $152 \mathrm{f}$.

125 Zeitweiliger Einsatz der Generale, Admirale und Offiziere als Soldat in der Truppe. Anordnung Nr. 4/59 des Ministers für Nationale Verteidigung, 3. Februar 1959, BA-MA, VA-01/5031, B1. $63 \mathrm{f}$.

126 Erfahrungsbericht über den vierwöchigen Einsatz als Soldat, 1959, BA-MA, VA-01/6144, Bl. 158.

127 Zeitweiliger Einsatz der Generale, Admirale und Offiziere als Soldat in der Truppe. Anordnung Nr. 4/59 des Ministers für Nationale Verteidigung, 3. Februar 1959, BA-MA, VA-01/5031, Bl. 65.

128 Protokoll der Parteiaktivtagung des Ministeriums für Nationale Verteidigung, 24.-26. Januar 1959, BA-MA, VA-P-01/510, Bl. 40. 
sind gar nicht interessiert, eine Massenbewegung zu entfalten, wir müssen doch an die Einsatzbereitschaft unserer Armee denken, wir müssen die bewußten Wege suchen, wie wir diesen Beschluß wirklich sinnvoll durchführen, damit für den Einzelnen, für das Kollektiv, für das sozialistische Bewußtsein etwas herauskommt. ... Wir müssen also diese Angelegenheit schnell korrigieren ... . "129

Die durch die Erziehungsmaßnahme entstandenen Probleme und die offenbar partiell vorhandene Tendenz zu ihrer Radikalisierung dürften auch den sowjetischen Militärberatern und damit der KPdSU nicht verborgen geblieben sein. Insofern erscheint es verständlich, daß Ulbricht versuchte, möglicher Kritik von sowjetischer Seite vorbeugend die Spitze zu nehmen. Am 27. Februar 1959 schrieb er an Chruschtschow, um die von der VBA übernommenen Erziehungsmaßnahmen zu erläutern und für Verständnis zu werben. Denn Ulbricht hatte während des XXI. Parteitages der KPdSU 1959 eine Unterhaltung mit dem Oberkommandierenden der Vereinten Streitkräfte, Marschall Konew, geführt, in der dieser „Zweifel an der Richtigkeit“ der Beschlüsse „über die zeitweilige Entsendung von Offizieren der Nationalen Volksarmee in die Produktion und die Entsendung aller Offiziere, die gesundheitlich dazu in der Lage sind, jährlich einen Monat in die unteren Einheiten der Armee" geäußert hatte. Konew brachte dabei anscheinend die Überzeugung zum Ausdruck, daß durch diese Maßnahmen die Ausbildung gemäß dem Ausbildungsbefehl nicht mehr gewährleistet sein werde ${ }^{130}$.

Ulbricht verwies gegenüber Chruschtschow jedoch darauf, daß die NVA im wesentlichen eine Kaderarmee sei, weshalb die Sicherheitskommission „keine Gefahr" im Hinblick auf die Erfüllung des Ausbildungsplanes sehe. Vor dem Hintergrund des vermutlichen Aufeinandertreffens zweier deutscher Armeen im Kriegsfall betonte er die Zielsetzung der Erziehungsmaßnahmen: Die DDR-Streitkräfte stünden „unter sehr komplizierten Bedingungen einem harten Gegner" gegenüber, weshalb die Treue der Offiziere und Soldaten zur Arbeiter- und Bauernmacht und zum Sozialismus "nicht weniger wichtig" sei als die militärische Ausbildung. Doch sei "diese Vorbereitung in der Truppe ungenügend"131. Ulbricht rechtfertigte den Dienst von Offizieren als Soldat in der Truppe nicht zuletzt mit dem Hinweis, daß so die „Überwindung spießbürgerlicher und bürokratischer Gewohnheiten“ gelingen werde ${ }^{132}$, die ihre Ursache vor allem darin hätten, „daß in der Zeit des Aufbaues" der NVA "die Ausbildung des Offiziersnachwuchses in den Händen von Militär-Fachleuten der alten Schule“ gelegen habe. „Das hatte“, so Ulbricht, „wie es nicht anders sein kann, seine negativen Seiten, zum Beispiel in bezug auf das Verhältnis zwischen Offizieren und Soldaten." 133

Honecker zeigte sich dementsprechend in weitgehender Übereinstimmung mit der chinesischen Linie davon überzeugt, daß die beschlossenen Erziehungsmaßnahmen dazu geeignet waren, „in absehbarer Zeit eine Umwälzung im Denken und Handeln" der Offiziere herbeizuführen. Er äußerte, es komme jetzt darauf an, "einen großen Sprung nach vorn zu machen“ in der politisch-ideologischen Festi-

129 Ebenda, Bl. $40 \mathrm{f}$.

130 Ulbricht an Chruschtschow, 27. Februar 1959, SAPMO-BArch, DY 30/J IV 2/202/66, Bl. 64.

131 Ebenda.

132 Ebenda, Bl. 66.

133 Ebenda. 
gung der bewaffneten Organe, in der Erhöhung ihrer militärischen Kampfkraft sowie der Festigung der Kampfgemeinschaft zwischen Offizier und Soldat ${ }^{134}$.

Generalmajor Heinz Hampel hat rückblickend bemerkt, die sowjetischen Offiziere hätten sich „über diese Maßnahmen sehr gewundert"135. In den sowjetischen Streitkräften gab es zur gleichen Zeit weder den Einsatz der Offiziere in der Produktion noch deren zeitweiligen Dienst als Soldat in der Truppe ${ }^{136}$. Es ist kaum vorstellbar, daß die KPdSU derartige Maßnahmen hätte verwirklichen wollen, da ihr klar gewesen sein dürfte, daß sie damit die Einsatzbereitschaft der Streitkräfte entscheidend geschwächt hätte.

Wegen der umfassenden Orientierung an der chinesischen Militärkonzeption zwischen 1957 und 1960 sowie der Intensität der politischen Durchdringung erscheint es insofern folgerichtig, von einer „Maoisierung“ der NVA innerhalb dieses Zeitraumes zu sprechen.

\section{Die Abkehr von der chinesischen Militärkonzeption 1960/1961 nach der Verschärfung des sino-sowjetischen Konfliktes}

Die Beziehungen zwischen der UdSSR und der VR China hatten sich nach dem XX. Parteitag der KPdSU 1956 zunehmend verschlechtert. Waren der Grund hierfür in erster Linie die unterschiedlichen Auffassungen bezüglich der Bewertung von Stalins Herrschaftssystem gewesen, so resultierte die weitere Verschärfung des Verhältnisses 1957/1958 vor allem aus der sowjetischen Weigerung, das chinesische Militär mit Atomwaffen auszustatten. In der Folgezeit ergaben sich eine Reihe ideologischer und politischer Differenzen zwischen beiden Seiten. Während Chruschtschow etwa die "friedliche Koexistenz" von Ost und West propagierte und eine atomare Rüstungsbegrenzung anstrebte, nannte Mao die atomare Bedrohung durch die USA einen „Papiertiger" und äußerte die Erwartung, daß Kriege unvermeidlich seien, solange der Imperialismus existiere. Der Streit entzündete sich aber auch an den Volkskommunen, die die KPdSU kritisch beurteilte ${ }^{137}$.

1960 spitzte sich der Konflikt zu. Im April erschienen in chinesischen Publikationen mehrere Artikel, in denen im Gegensatz zur sowjetischen Position vor allem die Auffassung vertreten wurde, ein möglicher Weltkrieg müsse nicht zwangsläufig die allgemeine Zerstörung der menschlichen Zivilisation bedeuten. Daher befürworteten die Chinesen auch „lokale Kriege“ zur Unterstützung revolutionärer Bewegungen trotz der drohenden Eskalation derartiger Konflikte. Auf der „Bukarester Konferenz der kommunistischen und Arbeiterparteien“ Ende Juni 1960 sollte dann der

134 Entwurf eines Diskussionsbeitrages von Honecker für die 4. Tagung des ZK der SED, 1959, SAPMO-BArch, DY 30/2516, o. Pag.

135 Hampel, Im Ministerium für Nationale Verteidigung, S. 188.

136 Werner Hübner, ehemaliger Mitarbeiter in der ZK-Abteilung für Sicherheitsfragen, hat geäußert, in den sowjetischen Streitkräften sei der Dienst von Offizieren und Generalen als Soldat in der Truppe „undenkbar" gewesen. Hübner, Zur Rolle der Partei in der Nationalen Volksarmee, S. 424.

137 Vgl. Ford, The Eruption of Sino-Soviet Politico-Military Problems, S. $100 \mathrm{ff}$. 
Versuch unternommen werden, die Kontroverse zu entschärfen. Statt dessen kam es jedoch zu massiven Auseinandersetzungen zwischen beiden Seiten, die jeweils auf ihren Standpunkten beharrten. Mit Ausnahme Chinas unterstützten letztlich alle auf der Konferenz vertretenen Parteien die sowjetische Sicht, es sei sowohl möglich, Kriege zu verhindern, als auch einen friedlichen Übergang vom Kapitalismus zum Sozialismus zu erreichen. Offenbar war das Zerwürfnis zwischen beiden Staaten so schwerwiegend, daß die Führung der KPdSU daraufhin im Juli 1960 beschloß, die in China arbeitenden sowjetischen Spezialisten umgehend zurückzubeordern ${ }^{138}$.

Die Verschärfung des sino-sowjetischen Konfliktes beeinflußte zwangsläufig auch die Beziehungen zwischen der DDR und der VR China. Die SED sah sich aufgrund massiven sowjetischen Drucks dazu gezwungen, sich nunmehr öffentlich von der Politik der KPCh zu distanzieren ${ }^{139}$. Dies geschah zum ersten Mal am 17. Juni 1960 in einem Artikel des „Neuen Deutschland“, der sich gegen chinesische Behauptungen wandte, als gelte „der in China beschrittene Weg von der Bodenreform über die LPG [Landwirtschaftliche Produktionsgenossenschaft] zu den Volkskommunen auch für andere Länder“. Dort hieß es, es dürfe „nicht der Eindruck erweckt werden“, als würde man „in der DDR zu Volkskommunen übergehen"140.

Bis zu diesem Zeitpunkt hatte es hinsichtlich der Volkskommunen jedoch eine weitgehende Übereinstimmung zwischen der SED und der KPCh gegeben, die auch dadurch nicht beeinträchtigt worden war, daß Chruschtschow die Volkskommunen im Juli 1959 offen verurteilt hatte. Trotz dieser Kritik der KPdSU war die Haltung der SED zu den Volkskommunen in der ersten Hälfte des Jahres 1960 zunächst uneingeschränkt positiv geblieben, was nicht zuletzt daran lag, daß dieses chinesische Experiment zeitgleich mit der Zwangskollektivierung der Bauern in der DDR stattfand ${ }^{141}$.

Anläßlich der Bukarester Konferenz signalisierte Ulbricht dann aber unmißverständlich die Abkehr von der Linie der KPCh, indem er den Chinesen unter anderem vorwarf, sie hätten versucht, in der DDR „eine Diskussion über die Volkskommunen“ zu provozieren. Er äußerte nunmehr: „Der Weg der Volkskommune ist absolut falsch für die Volksdemokratien."142 Diese Auffassung ließ bei den Chinesen keine Zweifel mehr hinsichtlich der neuen Position der SED aufkommen ${ }^{143}$.

138 Day, China and the Soviet Union 1949-84, S. $17 \mathrm{ff}$.

139 Christoph Kleßmann hat geäußert, es bleibe unklar, warum die SED „zum Jahresende 1959 so abrupt die Kollektivierungskampagne beschleunigt und 1960 rigoros innerhalb von wenigen Monaten zu Ende geführt" habe. Kleßmann, Zwei Staaten, eine Nation, S. 315. In Anbetracht der ab Mitte 1959 ausdrücklich ablehnenden Haltung Chruschtschows gegenüber den Volkskommunen und der von der SED immer wieder betonten ideologischen Nähe dieses Experiments zur Zwangskollektivierung in der DDR dürfte die SED-Führung zu der Überzeugung gelangt sein, ihre Kampagne schnell abzuschließen, bevor diese infolge der sich verschlechternden sino-sowjetischen Beziehungen in ihrem Fortgang eventuell behindert worden wäre.

140 Zur Klärung einer Frage, S. 3.

141 Die DDR und China 1949 bis 1990 , S. $102 \mathrm{f}$.

142 Rede des Genossen Walter Ulbricht über die Notwendigkeit eines Meinungsaustausches zwischen den kommunistischen und Arbeiterparteien der sozialistischen Länder über Fragen der internationalen Lage [Bukarester Konferenz der kommunistischen und Arbeiterparteien der sozialistischen Länder, 24.-26. Juni 1960], in: Die DDR und China 1949 bis 1990, S. 118.

143 Die ZK-Abteilung für Internationale Verbindungen befand im nachhinein, 1960 hätten sich 
Ulbrichts Distanzierung von der Politik der VR China hatte zugleich auch Auswirkungen auf die Adaption der chinesischen Militärkonzeption durch die SED. Dieser Ansatz war jetzt gezwungenermaßen einer Revision zu unterziehen ${ }^{144}$. Auf der 2. Sitzung des Nationalen Verteidigungsrates am 15. Juni 1960 wurde dementsprechend die „Änderung“ der Beschlüsse über die „Freistellung von Offizieren zur Aneignung von Produktionserfahrungen in der sozialistischen Produktion" vom 30. Juli 1958 sowie über die „zeitweilige Dienstleistung der Offiziere, Generale und Admirale als Soldat bezw. Unteroffizier in der Truppe" vom 20. Januar 1959 beschlossen ${ }^{145}$.

Augenfällig ist dabei die zeitliche Nähe dieses Beschlusses zu der am 17. Juni $1960 \mathrm{im}$ „Neuen Deutschland“ erstmals geäußerten Kritik der SED an den chinesischen Volkskommunen ${ }^{146}$. Die Vermutung liegt nahe, daß die SED-Führung zu der Überzeugung gelangt war, sich nicht im allgemeinen von der Politik der KPCh distanzieren zu können, ohne - wenigstens intern - auch eine Abkehr von der chinesischen Militärkonzeption einzuleiten. Trotz der Tatsache, daß der Beschluß im Nationalen Verteidigungsrat gefällt wurde, dürfte die KPdSU von ihm Kenntnis erlangt haben. In Anbetracht der inhaltlich nur geringen Änderungen an den alten Regelungen ging es der SED vermutlich vor allem darum, ein politisches Signal in Richtung der sowjetischen Führung auszusenden. Grundsätzlich hielt die SEDFührung an den Maßnahmen zunächst jedoch fest, schränkte sie aber ein.

So sollten die Absolventen der Offiziersschulen, die nicht mindestens ein Jahr in der Produktion tätig gewesen waren, anstatt für ein Jahr nur noch für rund sechs Monate „zur Aneignung von sozialistischen Produktionserfahrungen“ nach Ende ihrer Ausbildung vom Dienst freigestellt werden. Hatten sie „am polytechnischen Unterricht an den allgemeinbildenden Schulen teilgenommen", wurde ihnen diese Zeit als Produktionstätigkeit angerechnet. Von den aktiven Offizieren der NVA ohne Produktionserfahrungen sollten „ausgehend von den gestellten Aufgaben für die Ausbildung und die Gewährleistung der Gefechts- und Einsatzbereitschaft" jährlich nur noch 25 Prozent für einen Monat in der Produktion eingesetzt werden. Zudem wurden neben Ärzten und Flugzeugführern jetzt unter anderem auch das fahrende Personal der Seestreitkräfte und ein Teil der technischen Offiziere von der Teilnahme an der Erziehungsmaßnahme befreit ${ }^{147}$.

in der chinesischen Politik „Tendenzen des Nationalismus und ein, wenn auch nicht offen vorgebrachter, Anspruch auf Allgemeingültigkeit der chinesischen Auffassungen, Erfahrungen und Methoden und damit faktisch ein noch unausgesprochener Führungsanspruch innerhalb der internationalen Arbeiterbewegung" gezeigt. Bemerkungen zur Außenpolitik der VR China im Jahre 1960, SAPMO-BArch, DY 30/IV 2/20/122, Bl. 294.

$144 \mathrm{Vgl}$. Storkmann, Das chinesische Prinzip in der NVA, S. $48 \mathrm{ff}$.

145 Protokoll der 2. Sitzung des Nationalen Verteidigungsrates der DDR, 15. Juni 1960, BA-MA, DVW 1/39459, Bl. $5 \mathrm{ff}$.

146 Am folgenden Tag wurde der SED-Führung durch Chruschtschow mitgeteilt, man habe die chinesische Regierung über den Entschluß in Kenntnis gesetzt, die rund 1500 sowjetischen Spezialisten aus der VR China abzuberufen. Chruschtschow an das ZK der SED, 18. Juli 1960, SAPMO-BArch, DY 30/J IV 2/202/280, o. Pag.

147 Änderung des Beschlusses vom 30. Juli 1958 über die Freistellung von Offizieren zur Aneignung von Produktionserfahrungen in der sozialistischen Produktion. Protokoll der 2. Sitzung des Nationalen Verteidigungsrates der DDR, 15. Juni 1960, BA-MA, DVW 1/39459, Bl. 5 f. 
Auch an dem Dienst als Soldat in der Truppe mußten fortan jährlich nur noch maximal 25 Prozent des Offiziersbestandes einer Einheit teilnehmen. Zudem dauerte der Einsatz in der Regel nur noch einen Monat. Zusätzlich zu der Gruppe von Offizieren, die schon vom Produktionseinsatz befreit war, blieben unter anderem auch Offiziershörer der Militärakademien und Hörer langfristiger Lehrgänge sowie Offiziere mit besonderen Qualifikationen oder Aufgabenstellungen als Wissenschaftler und Spezialisten vom Dienst in der Truppe ausgenommen. In diesem $\mathrm{Zu}$ sammenhang wies der Nationale Verteidigungsrat darauf hin, daß der Beschluß so durchzuführen sei, „daß die Ausbildung, Dienstdurchführung und Gefechtsbereitschaft der Stäbe, Truppenteile und Einheiten jederzeit aufrechterhalten " bleibe ${ }^{148}$.

Die Änderungen lassen die Absicht der SED-Führung erkennen, die Erziehungsmaßnahmen in ihrem Umfang soweit zu reduzieren, daß sie die Einsatzbereitschaft der Streitkräfte nur noch geringfügig beeinträchtigen konnten. Offenkundig trat hier die Intention zutage, die politische Durchdringung der NVA zurückzunehmen und verstärkt die Interessen der militärischen Truppenführung zu berücksichtigen. Anscheinend hatte der Nationale Verteidigungsrat die Änderung der Beschlüsse nicht zuletzt auf der Grundlage der Berichte der militärischen Truppenführung hinsichtlich der Anwendung der Erziehungsmaßnahmen gefällt.

So wurde im entsprechenden Bericht des Kommandos Seestreitkräfte die Befürchtung geäußert, ein ,jährlich sich wiederholender 1-monatiger Dienst eines jeden Offiziers der Seestreitkräfte als Matrose“ führe „mit großer Wahrscheinlichkeit - bedingt durch die angespannten Stellenpläne und die nicht vorhandene Kaderreserve - nicht zu der erhofften wesentlichen Erhöhung der Einsatz- und Gefechtsbereitschaft der Stäbe, Verbände und Einheiten der Seestreitkräfte, sondern zu ihrer Verminderung " 149 .

Der SED erschien es zu diesem Zeitpunkt jedoch anscheinend nicht als zwingend, die von der VBA übernommenen Erziehungsmaßnahmen grundsätzlich zu verurteilen. Der Nationale Verteidigungsrat gelangte vielmehr zu einer durchweg positiven Würdigung der durch die Maßnahmen erzielten Ergebnisse, die in Teilen eine rechtfertigende Tendenz aufwies. Das Gremium konstatierte, die Produktionstätigkeit habe sich vorteilhaft auf die Entwicklung des sozialistischen Bewußtseins der Offiziere ausgewirkt. Fast alle seien dadurch „politisch und auch persönlich reifer geworden". Aufgrund ihres hohen Arbeitseinsatzes hätten sich die Offiziere „sehr schnell das Vertrauen der Werktätigen erworben“, die daraufhin „mit Achtung von ,ihren' Offizieren als den Arbeiter $[n]$ in Uniform" gesprochen hätten. Es wurde nachdrücklich betont: „Die Erfahrungen zeigen, daß diese Maßnahme zweckmäßig und wirksam ist. " 150

148 Änderung des Beschlusses vom 20. Januar 1959 über die zeitweilige Dienstleistung der Offiziere, Generale und Admirale als Soldat bzw. Unteroffizier in der Truppe. Protokoll der 2. Sitzung des Nationalen Verteidigungsrates der DDR, 15. Juni 1960, BA-MA, DVW 1/39459, Bl. $7 \mathrm{f}$.

149 Bericht und Vorschläge zur Durchführung des Beschlusses vom 20. Januar 1959 über die zeitweilige Dienstleistung der Offiziere, Generale und Admirale als Soldat bzw. Unteroffizier in der Truppe. Protokoll der 2. Sitzung des Nationalen Verteidigungsrates der DDR, 15. Juni 1960, BA-MA, DVW 1/39459, Bl. 66.

150 Bericht und Vorschläge zur Durchführung des Beschlusses vom 30. Juli 1958 über die Freistellung von Offizieren zur Aneignung von Produktionserfahrungen in der sozialistischen 
Auch der Einsatz von Offizieren als Soldat habe „auf die gesamte politische und militärische Ausbildungs- und Erziehungsarbeit in der Truppe einen positiven Einfluß" gehabt, hieß es. Die Offiziere hätten „wertvolle Erfahrungen“ für die Verbesserung ihrer Leitungstätigkeit und die Erziehungs- und Ausbildungsarbeit gesammelt. In dieser Hinsicht habe sich das „Bewußtsein der Offiziere, ihre politische Aktivität sowie ihre Autorität und ihr persönliches Verhalten“ positiv entwickelt. Der Nationale Verteidigungsrat äußerte auch hier: „Die Erfahrungen beweisen, daß die Maßnahme geeignet ist, die sozialistischen Beziehungen zwischen den Soldaten und Offizieren schneller und wirksamer zu verbessern."151

In den folgenden Monaten nach dem Rückzug der sowjetischen Spezialisten blieb das Verhältnis zwischen der UdSSR und der VR China weiter angespannt. Nach der offen geäußerten Kritik auf der Bukarester Konferenz im Juni 1960 vollzog die SED-Führung in einem Brief an das ZK der KPCh vom 6. September desselben Jahres jetzt auch formal den Bruch mit den politischen Positionen der Chinesen. Das ZK der SED distanzierte sich vor allem von der Auffassung der chinesischen KP, in der modernen Epoche des Imperialismus, der Kriege und Revolutionen gebe es eine „schicksalhafte Unvermeidlichkeit der Kriege “152. Diese These, so die SED, müsse „zwangsläufig zu fehlerhaften, nicht marxistisch-leninistischen Konzeptionen in den Fragen der Strategie und Taktik führen" 153 . Auch die Ansicht, es gebe neben der „Alternative friedliche Koexistenz oder Krieg ... einen dritten Weg der kleinen Kriege und des kalten Krieges“ wies die SED als „antimarxistisch und außerordentlich schädlich“ zurück. Bekanntlich arbeiteten die "Adenauer-Regierung und der Bonner-Generalstab ... Pläne für sogenannte, lokale 'oder ,begrenzte' Kriege gegen die DDR aus"154. Auch kritisierte man den vermeintlichen Anspruch der KPCh, ihren Auffassungen über die Volkskommunen den „Charakter eines allgemeingültigen, grundlegenden Leitsatzes des Marxismus-Leninismus über den Aufbau des Sozialismus und Kommunismus auf dem Dorfe zu geben"155. Schließlich bekannte sich die SED unmißverständlich zu den Positionen der KPdSU, indem sie konstatierte, „die Meinungsverschiedenheiten in wichtigen Fragen der internationalen Politik" existierten nicht nur zwischen der KPdSU und der KPCh - wie von letzterer behauptet wurde - „sondern zwischen der Führung der KPCh und allen anderen Bruderparteien" 156 .

Im November 1960 unternahmen dann 81 kommunistische Parteien im Rahmen einer langfristig vorbereiteten Konferenz in Moskau einen erneuten Versuch, den sino-sowjetischen Konflikt zu entschärfen. Die chinesische Delegation unter Leitung von Deng Xiaoping verneinte jetzt zwar die Unvermeidlichkeit eines Weltkrieges,

Industrie, Land- und Forstwirtschaft. Protokoll der 2. Sitzung des Nationalen Verteidigungsrates der DDR, 15. Juni 1960, BA-MA, DVW 1/39459, Bl. 59.

151 Bericht und Vorschläge zur Durchführung des Beschlusses vom 20. Januar 1959 über die zeitweilige Dienstleistung der Offiziere, Generale und Admirale als Soldat bzw. Unteroffizier in der Truppe. Protokoll der 2. Sitzung des Nationalen Verteidigungsrates der DDR, 15. Juni 1960, BA-MA, DVW 1/39459, Bl. $64 \mathrm{f}$.

$152 \mathrm{ZK}$ der SED an das ZK der KPCh, 6. September 1960, SAPMO-BArch, DY 30/J IV 2/202/279, o. Pag.

153 Ebenda.

154 Ebenda.

155 Ebenda.

156 Ebenda. 
hielt ihn bei anhaltender Existenz des Kapitalismus aber weiter für wahrscheinlich. Die KPCh warf der sowjetischen Seite zudem vor, die Möglichkeit des friedlichen Überganges zum Sozialismus zu überschätzen. Schließlich konstatierte man, die KPdSU sei zwar die führende Partei des kommunistischen Lagers, grundsätzlich seien die Parteien aber unabhängig und gleichberechtigt; mithin könne die KPdSU nicht beanspruchen, daß die Beschlüsse des Kongresses für alle Parteien bindend $\operatorname{seien}^{157}$.

In der Abschlußerklärung vom 25. November 1960 behielt letztlich jedoch die KPdSU mit ihrer Sicht die Oberhand; einzig im Rahmen der Formulierungen gab es einige Zugeständnisse. So räumte man zwar ein, daß sich die aggressive Natur des Imperialismus nicht geändert habe. Durch die gemeinsamen Anstrengungen des sozialistischen Lagers könne ein Weltkrieg aber verhindert werden. Der friedliche Übergang zum Sozialismus sei auch deshalb möglich, weil die Politik der friedlichen Koexistenz der Systeme von Teilen der Bourgeoisie der entwickelten kapitalistischen Staaten befürwortet werde. Im Hinblick auf das eigene Lager wurden erneut „Revisionismus“, aber auch „Dogmatismus" und "Sektierertum“ als Hauptgefahren in der Entwicklung einzelner kommunistischer Parteien bezeichnet ${ }^{158}$.

Dieser Hinweis der Moskauer Erklärung dürfte nicht nur der KPCh gegolten haben; er konnte ebenso als Warnung an die übrigen Parteien verstanden werden. Fortan orientierte sich die SED ausschließlich an der KPdSU. Alle in Anlehnung an die VR China entwickelten politischen Experimente traten in den folgenden Monaten eindeutig in den Hintergrund. So wurde auf der 11. ZK-Tagung vom 15. bis 17. Dezember 1960 beschlossen, die umstrittene Übernahme von Elementen der chinesischen Militärkonzeption in der NVA zu beenden ${ }^{159}$.

Im Anschluß hob das Politbüro am 17. Januar 1961 den Grundsatzbeschluß des V. Parteitages vom Juli 1958 über die regelmäßige Teilnahme der Funktionäre der Partei, des Staatsapparates und der Massenorganisationen an der Produktionsarbeit auf. Zur Begründung hieß es, die Funktionäre hätten „hierbei wertvolle Erfahrungen in der praktischen Arbeit für ihre eigene Tätigkeit gesammelt und ein engeres Verhältnis zu den Werktätigen hergestellt", so daß die Maßnahme „im wesentlichen als erfüllt betrachtet" werden könne. Das Politbüro machte daher dem ZK den Vorschlag, „diesen Beschluß zu ändern“, was jedoch eine Umschreibung für seine faktische Aufhebung war. Zudem führte man an, die „neuen Aufgaben“ könnten „nur durch eine bedeutende Erhöhung der Qualität und der Wissenschaftlichkeit in der Arbeit der Partei- und Staatsfunktionäre" erreicht werden. Es bleibe jedoch notwendig, denjenigen, die noch nie in der Produktion gearbeitet hätten, „weiterhin die Gelegenheit zu geben“, sich durch eine zeitweilige Tätigkeit Produktionserfahrungen anzueignen 160 .

Auf der Grundlage dieses Beschlusses ordnete der Minister für Nationale Verteidigung daraufhin am 1. Februar 1961 mit sofortiger Wirkung an, „keine Offiziere

157 Day, China and the Soviet Union 1949-84, S. $21 \mathrm{f}$.

158 Ebenda, S. $22 \mathrm{f}$.

159 Otto, Über die Rolle des Zentralkomitees, S. 73.

160 Änderung des Beschlusses der 4. Tagung des ZK der SED über den zeitweiligen körperlichen Einsatz der Mitarbeiter des Partei- und Staatsapparates und der Massenorganisationen. Protokoll Nr. 3/61 der Sitzung des Politbüros des ZK der SED, 17. Januar 1961, SAPMO-BArch, DY 30/J IV 2/2/745, Bl. 7, $142 \mathrm{f}$. 
mehr zum Dienst als Soldat bzw. Unteroffizier in der Truppe zu kommandieren oder zur Aneignung von sozialistischen Produktionserfahrungen freizustellen" und diese Maßnahmen bis spätestens 30. Juni 1961 zu beenden ${ }^{161}$. Es hieß, der Dienst als Soldat habe zur „weiteren Festigung eines sozialistischen Vertrauensverhältnisses zwischen den Soldaten, Unteroffizieren und Offizieren beigetragen“. Auch die Produktionsarbeit habe bei den Offizieren insbesondere zu einer „Festigung des Klassenbewußtseins" und zur "wesentlichen Verbesserung der Arbeit mit den Unterstellten geführt". In Übereinstimmung mit dem Politbürobeschluß vom 17. Januar 1961 wurde daher festgestellt: „Diese Ergebnisse gestatteten es dem Zentralkomitee der Sozialistischen Einheitspartei Deutschlands, zu beschließen, die gestellten Aufgaben als erfüllt zu betrachten und von einem weiteren Festhalten an den auf diesem Gebiet erlassenen Beschlüssen abzusehen." 162

Zum Zeitpunkt des Mauerbaus am 13. August 1961 spielten die politischen Konzepte der KPCh in der Politik der SED keine erkennbare Rolle mehr. Auch die Orientierung an der chinesischen Militärkonzeption war endgültig beendet worden. In der Folgezeit avancierte sie zu einem Tabu-Thema ${ }^{163}$. Der Aufwand, der im Zusammenhang mit den Erziehungsmethoden betrieben worden war, hatte letztlich in keinem Verhältnis zu den erzielten Ergebnissen etwa im Hinblick auf das verbesserte Verhalten der NVA-Offiziere gestanden ${ }^{164}$. Zudem wirkten sich die Maßnahmen äußerst kontraproduktiv auf die Steigerung der Einsatzbereitschaft der DDRStreitkräfte aus, die die SED seit 1961 entsprechend den Forderungen der KPdSU mit Nachdruck anstrebte. Im Oktober 1962 kam es dann zur ersten Reise einer Militärdelegation der NVA unter Leitung Hoffmanns in die UdSSR ${ }^{165}$. Damit fand die Ableehr der SED von der Militärpolitik der VR China schließlich auch symbolisch ihren Abschluß.

161 Die Dienstleistung der Offiziere als Soldat bzw. Unteroffizier in der Truppe, S. 1.

162 Ebenda.

163 Wenzke, Die Nationale Volksarmee, S. 441. Gewissermaßen als ein Überrest der chinesischen Militärkonzeption blieb zunächst noch die formal starke Stellung der Parteisekretäre erhalten. Diese wurde durch die neue „Instruktion für die Parteiorganisationen der SED in der NVA und für die Politorgane der NVA“ vom 5. November 1963 schließlich jedoch auch beseitigt. Vgl. Kap. VIII.2. dieser Studie.

164 Vgl. Kap. VI. dieser Studie.

165 Zeittafel zur Militärgeschichte, S. 164. 